\title{
Osthole-Loaded Nanoemulsion Enhances Brain Target in the Treatment of Alzheimer's Disease via Intranasal Administration
}

\author{
Yilei Song $\mathbb{D},{ }^{1}$ Xiangyu Wang, ${ }^{1}$ Xingrong Wang, ${ }^{1}$ Jianze Wang, ${ }^{1}$ Qiulian Hao, ${ }^{1}$ Jifu Hao $\mathbb{D},{ }^{1}$ \\ and Xueqin Hou (iD) ${ }^{2}$ \\ ${ }^{1}$ College of Pharmacy, Shandong First Medical University \& Shandong Academy of Medical Sciences, Taian, Shandong 271016, China \\ ${ }^{2}$ Institute of Pharmacology, Shandong First Medical University \& Shandong Academy of Medical Sciences, Taian, \\ Shandong 271016, China
}

Correspondence should be addressed to Jifu Hao; 15864769568@163.com and Xueqin Hou; houxueqin09@126.com

Received 29 August 2020; Revised 4 January 2021; Accepted 9 January 2021; Published 25 January 2021

Academic Editor: Fabiana Morroni

Copyright (c) 2021 Yilei Song et al. This is an open access article distributed under the Creative Commons Attribution License, which permits unrestricted use, distribution, and reproduction in any medium, provided the original work is properly cited.

\begin{abstract}
Osthole (OST) is a natural coumarin compound that exerts multiple pharmacologic effects. However, the poor water solubility and the low oral absorption of OST limit its clinical application for the treatment of neurologic diseases. A suitable preparation needs to be tailored to evade these unfavourable properties of OST. In this study, an OST nanoemulsion (OST-NE) was fabricated according to the pseudoternary phase diagram method, which was generally used to optimize the prescription in light of the solubility of OST in surfactants and cosurfactants. The final composition of OST-NE was 3.6\% of ethyl oleate as oil phase, $11.4 \%$ of the surfactant (polyethylene glycol ester of 15-hydroxystearic acid: polyoxyethylene 35 castor oil =1:1), 3\% of polyethylene glycol 400 as cosurfactant, and $82 \%$ of the aqueous phase. The pharmacokinetic study of OST-NE showed that the brain-targeting coefficient of OST was larger by the nasal route than that by the intravenous route. Moreover, OST-NE inhibited cell death, decreased the apoptosis-related proteins (Bax and caspase-3), and enhanced the activity of antioxidant enzymes (superoxide dismutase and glutathione) in L-glutamate-induced SH-SY5Y cells. OST-NE improved the spatial memory ability, increased the acetylcholine content in the cerebral cortex, and decreased the activity of acetylcholinesterase in the hippocampus of Alzheimer's disease model mice. In conclusion, this study indicates that the bioavailability of OST was improved by using the OST-NE via the nasal route. A low dose of OST-NE maintained the neuroprotective effects of OST, such as inhibiting apoptosis and oxidative stress and regulating the cholinergic system. Therefore, OST-NE can be used as a possible alternative to improve its bioavailability in the prevention and treatment of Alzheimer's disease.
\end{abstract}

\section{Introduction}

Alzheimer's disease (AD) is a common neurodegenerative disease characterized by memory impairment and cognitive dysfunction. The pathogenesis of $\mathrm{AD}$ is complex, including cholinergic dysfunction, oxidative stress, glutamate excitotoxicity, and amyloid $\beta$ accumulation $[1,2]$. To date, existing medications are symptomatic, and there are still no ideal therapeutic agents that can fundamentally cure AD [3].

Osthole (OST) is a natural coumarin compound extracted from the seed of Cnidium monnieri (L.) Cuss [4]. OST exerts various pharmacologic actions, such as antiinflammation [5], antioxidative stress [6], antiapoptosis [7], and antitumor activities [8]. Many studies have disclosed that
OST can prevent glutamate-induced neurotoxicity and neuronal loss and can be used to treat central nervous system disorders by modifying oxidative stress [9] and other molecular pathways [10-12]. In addition, OST also betters cognitive function and improves neuronal recovery $[6,13]$. However, the poor water solubility and the low bioavailability $[14,15]$ hinder the clinical application of OST for the treatment of neurologic disorders. Furthermore, OST is $\mathrm{pH}$-sensitive [16], which also affects its application. Generally, coumarin components are unstable to acids and prone to isoamyl double bond cracking. Although OST is also a natural coumarin compound, there is a pyranone ring with the property of unsaturated lactone, and the substituent in C7 position is methoxy structure in the molecular structure. The 
substituents in the $\mathrm{C} 7$ position increase the steric hindrance effect, thus improving its $\mathrm{pH}$ sensitivity for the drug.

Nanoemulsions are generally considered to be ideal drug carriers for the delivery of poorly water-soluble drugs to improve the bioavailabilities [17]. As a colloidal system, nanoemulsions are composed of oil, water, and a mixture of surfactants and cosurfactants [18]. The presence of oil and surfactants offers the highest drug solubilizing capability for hydrophobic drugs. The oil loaded with a drug is thoroughly dispersed into the water with the aid of surfactants and cosurfactants to form small droplets with a particle size in the nanometer range. Therefore, the solubility and bioavailability of poorly water-soluble drugs, such as OST, can be correspondingly enhanced due to the formation of nanoemulsions. Moreover, recent studies have shown neuroprotective effects were exerted by using naringenin nanoemulsion in the AD model [19] and in Parkinson's disease model [20], suggesting that nanoemulsion is a promising approach for developing new agents against neurodegenerative diseases.

The delivery of a drug to the brain via the oral route can be limited by the blood-brain barrier (BBB), resulting in unsatisfying bioavailability [2]. Thus, an alternative route via the nasal administration has emerged, since the nose-tobrain path can provide a direct brain-targeted delivery of drugs [2]. Moreover, nasal brain transport of nanocomposites has been reported to be an available strategy [21]. Therefore, the development of drug-loaded nanoemulsions via the nose-to-brain path may enhance the brain targeting of a drug and improve the bioavailability. For example, Bhattamisra et al. [22] reported that intranasal administration of rotigotine-loaded chitosan nanoparticles enhanced braintargeting efficiency and drug bioavailability in rats. Other studies also showed that the application of nanoemulsion facilitated the delivery of donepezil and memantine (two approved drugs for treating $\mathrm{AD}$ ) to the brain via the intranasal route $[23,24]$. These studies suggest that nanotechnology is a potential approach to enhance the nose-to-brain delivery of drugs in the treatment of AD.

The aim of this study is to develop OST-loaded nanoemulsion that can be delivered via the nasal route and to investigate whether this strategy can improve the OST bioavailability to treat $\mathrm{AD}$. Thus, the OST nanoemulsions (OST-NE) were tailored and the physicochemical properties were characterized. Then, the pharmacokinetic features of OST-NE via the intranasal (IN) and intravenous (IV) routes were comparatively investigated. Finally, the anti-AD effects of OST-NE were determined in L-glutamate-induced SHSY5Y neuroblastoma cells and in scopolamine-induced AD mice.

\section{Materials and Methods}

2.1. Determination of Solubility and Lipid-Water Partition Coefficient of OST. Various types of oils, emulsifiers, and coemulsifiers were chosen as solvents to determine the saturated solubility of OST. Briefly, a number of OST powders (Nantong Feiyu Biological Technology Co., LTD., Nantong, China) were added to $0.5 \mathrm{~mL}$ of oils (ethyl oleate, isopropyl myristate), surfactant (polyethylene glycol ester of 15hydroxystearic acid (HS-15), polyoxyethylene 35 castor oil (EL-35), Tween-80, the blended surfactant of HS-15 and EL-35 at a ratio of $1: 1$ ), and cosurfactant (polyethylene glycol 400 (PEG400), 1,2-propanediol, absolute ethanol), respectively. After stirring with a magnetic stirrer for 30 minutes, the mixture was shaken at $37^{\circ} \mathrm{C}$ for 48 hours and then centrifuged at $12000 \mathrm{r} / \mathrm{min}$ for 15 minutes. The supernatant was collected and diluted with methanol, and the content of OST was determined by high-performance liquid chromatography (HPLC) [25]. The chromatographic system consisted of a Shimadzu LC-10AT solvent delivery pump (Shimadzu, Kyoto, Japan) equipped with a $20 \mu \mathrm{L}$ loop and a $\mathrm{UV}$ visible detector. Welchrom $\mathrm{C}_{18}$ column $(4.6 \times 200 \mathrm{~nm}$, $5 \mu \mathrm{m})$ analytical column was used. The eluate was monitored at $322 \mathrm{~nm}$. The mobile phase was methanol and water $(80: 20, v / v)$ with a flow speed of $1.0 \mathrm{~mL} / \mathrm{min}$ at room temperature.

The lipid-water partition coefficient of OST was assayed with an octanol/water extraction method followed by HPLC analysis. Briefly, $40 \mathrm{mg}$ of OST powder was dissolved in $2 \mathrm{~mL}$ distilled-water-saturated octanol in $5 \mathrm{~mL}$ polypropylene centrifugal tubes. Then, $2 \mathrm{~mL}$ of octanol-saturated distilled water was added into each tube. Each of the tubes was vibrated vigorously for 15 minutes and then shaken for 72 hours to reach equilibrium at $37^{\circ} \mathrm{C}$. After centrifugation, the content of OST in the octanol and water was determined, respectively. The logarithm value of the lipid-water partition coefficient $(\log P)$ was calculated according to the following equation:

$$
\log P=\log \frac{C_{\text {oil }} \times V_{\text {oil }}}{C_{\text {water }} \times V_{\text {water }}} .
$$

2.2. Construction of Pseudoternary Phase Diagram. Pseudoternary phase diagrams were created using the aqueous titration method. The ratios of mixed surfactant to cosurfactant (Km values) were set as $1: 1,2: 1,3: 1$, and $4: 1$, respectively. The weight ratios of oil to the mixed surfactants at each $\mathrm{Km}$ were varied as $1: 9,2: 8,3: 7,4: 6,5: 5,6: 4,7: 3,8: 2$, and $9: 1$. After the oil and the mixed emulsifier were thoroughly merged, the mixture was titrated with distilled water under moderate stirring, and the amount of water was recorded when the transparent or translucent nanoemulsions appeared [26]. The pseudoternary phase diagrams were plotted according to the proportion of each component. Finally, the composition of OST-NE was 3.6\% of ethyl oleate as oil phase, $11.4 \%$ of the surfactant (HS-15 and EL-35, ratio $1: 1), 3 \%$ of PEG400 as cosurfactant, and $82 \%$ of the aqueous phase.

2.3. Physicochemical Characterization of OST-NE. Physical stability determination: OST-NE was centrifuged at $15000 \mathrm{r} / \mathrm{min}$ for 15 minutes. Whether OST-NE was precipitated, delaminated, or turbid after centrifugation was observed.

Particle size measurement: the zeta potential and particle size were determined by a Malvern Nano series particle size 
analyzer (Malvern, UK). The data analysis was performed using the Malvern Zetasizer software (Malvern, UK).

Type identification: the type of nanoemulsion was determined by using the oil dye Sudan Red III (red) and the watersoluble dye methylene blue (blue). The diffusion speed of the two dyes in the nanoemulsion was observed.

Morphological analysis: a drop of OST-NE was added on a carbon-coated copper grid and stained with $1 \%$ phosphotungstic acid. After drying, the morphology of the OST-NE was visualized using JEM-1200EX transmission electron microscopy (TEM) (JEOL, Tokyo, Japan).

2.4. Stability of OST-NE. The prepared OST-NE was placed at $25^{\circ} \mathrm{C}$ for 25 days. The particle size, polydispersity index (PDI), and potential of OST-NE were measured on $0,5,10$, 15,20 , and 25 days.

2.5. Sterilization of OST-NE. To screen a proper sterilization method, OST-NE was sterilized by three sterilization methods, including high temperature autoclaving, ultraviolet (UV) irradiation, and microporous membrane. The stability of the OST-NE and bacteria in the OST was detected after sterilization.

2.6. In Vitro Drug Release Test. The OST-NE release test was performed using the intelligent dissolution test apparatus ZRS-8G (Tianjin Tianda Tianfa Technology Co., Ltd., Tianjin, China). The OST-NE or OST suspension (containing $4 \mathrm{mg}$ OST) was placed in a dialysis bag (8000-14000 MW cutoff). The test was conducted in $200 \mathrm{~mL}$ of Simulated Nasal Electrolyte Solution (SNES) containing 1\% Tween-80 at $100 \mathrm{r} / \mathrm{min}$ and $37 \pm 0.5^{\circ} \mathrm{C}$. The SNES (pH 5.5) was composed of $7.45 \mathrm{mg} / \mathrm{mL} \mathrm{NaCl}, 1.29 \mathrm{mg} / \mathrm{mL} \mathrm{KCl}$, and $0.32 \mathrm{mg} / \mathrm{mL}$ $\mathrm{CaCl}_{2}-2 \mathrm{H}_{2} \mathrm{O}$. An aliquot $(0.5 \mathrm{~mL})$ of the dissolution medium was withdrawn at $0.25,0.5,1,2,4,6,8,10,12,24,36,48,60$, and 72 hours, respectively. The dissolution medium was replenished with an equal volume of fresh isothermal SNES after each sampling. All the dissolution samples were filtered with a $0.22 \mu \mathrm{m}$ Millipore filter before analysis by HPLC.

2.7. Pharmacokinetic Study. Animal experiments throughout the study were approved by the Institutional Animal Ethics Committee of Shandong First Medical University and Shandong Academy of Medical Sciences. Kunming mice (20 $\pm 2 \mathrm{~g})$ were purchased from the China Biologic Products Holdings, Inc. Mice were fed with a standard diet and had free access to distilled water. After fasting overnight, the mice were randomly divided into two groups. One group was administered with a single dose of OST-NE $(40 \mathrm{mg} / \mathrm{kg})$ by the IV route. Another group was administered with a single dose of OST-NE $(10 \mathrm{mg} / \mathrm{kg})$ by the IN route. Blood samples were collected through the orbital vein at $5,15,30,60,120,180,240$, and 360 minutes after administration. Then, the mice were dislocated and perfused transcardially with normal saline. The brains were removed and homogenized in saline. The blood samples were centrifuged at $3000 \mathrm{r} / \mathrm{min}$ for 10 minutes. Then, $100 \mu \mathrm{L}$ of plasma or brain tissue homogenate was placed in a centrifuge tube, followed by adding $300 \mu \mathrm{L}$ acetonitrile. After being vortexed for 5 minutes, the samples were centrifuged at $10000 \mathrm{r} / \mathrm{min}$ for 10 minutes. The supernatant was collected. $\mathrm{NaCl}$ was added to the supernatant, and the sample was centrifuged at $10000 \mathrm{r} / \mathrm{min}$ for 10 minutes. The OST concentrations in the plasma and brain were measured using HPLC at $322 \mathrm{~nm}$. DAS 2.2.1 software (DAS Studio, Shanghai, China) was used to calculate the pharmacokinetic parameters in plasma and brain tissue following IN and IV administration. To evaluate the brain targeting after IN administration, drug-targeting efficiency (DTE\%) was calculated by formula (2), and drug-targeting percent (DTP\%) [27] was calculated by formula (3).

$$
\begin{gathered}
\mathrm{DTE} \%=\frac{\left[\left(\mathrm{AUC}_{\text {brain }} / \mathrm{AUC}_{\text {blood }}\right)_{\text {i.n. }}\right]}{\left[\left(\mathrm{AUC}_{\text {brain }} / \mathrm{AUC}_{\text {blood }}\right)_{\text {i.v. }}\right]} \times 100, \\
\mathrm{DTP} \%=\left[\frac{B_{\text {i.n. }}-B_{x}}{B_{\text {i.n. }}}\right] \times 100, \\
B_{x}=\left(\frac{B_{\text {i.v. }}}{P_{\text {i.v. }}}\right) \times P_{\text {i.n. }},
\end{gathered}
$$

where $P_{\text {i.v. }}, B_{\text {i.v. }}, P_{\text {i.n. }}$, and $B_{\text {i.n. }}$ denote the area under the curve (AUC) from time zero to time $t\left(\mathrm{AUC}_{0-t}\right)$ of OSTNE in plasma $(P)$ and brain $(B)$ tissue that were obtained after IV and IN administration, respectively. $B_{x}$ represents the brain AUC fraction contributed by systemic circulation through the blood-brain barrier (BBB) after IN administration.

2.8. Cell Culture and Treatments. The human neuroblastoma cell line SH-SY5Y was purchased from Capital Medical University (Beijing, China). SH-SY5Y cells were cultured with high-glucose Dulbecco's modified Eagle's medium (Hyclone, Logan, UT, USA) supplemented with $10 \%$ fetal bovine serum (EVERY GREEN, Zhejiang Tianhang Biotechnology Co., Ltd., Hangzhou, China) and $100 \mathrm{U} / \mathrm{mL}$ penicillin plus $100 \mu \mathrm{g} / \mathrm{mL}$ streptomycin (Gibco, USA) at $37^{\circ} \mathrm{C}$ in a humidified $5 \% \mathrm{CO}_{2}$ atmosphere in an incubator (WIGGENS, Germany).

To determine the condition of L-glutamate (L-Glu) in inducing excitotoxicity, SH-SY5Y cells were exposed to LGlu (Solarbio Life Sciences, Beijing, China) at different concentrations $(5,10,15,20,25,30,35$, and $40 \mathrm{mmol} / \mathrm{L})$ for different durations $(4,6,8,10$, and 12 hours). MTT assay was used to determine the cell viability. Finally, an incubation of L-Glu at $30 \mathrm{mmol} / \mathrm{L}$ for 6 hours was chosen to establish the L-Glu-induced SH-SY5Y cell model.

Next, the effects of blank nanoemulsion on L-Gluinduced SH-SY5Y cells were investigated. SH-SY5Y cells were seeded in 96-well culture plates $\left(2 \times 10^{4}\right.$ cells/well $)$ and cultured for 24 hours. Then, the cells were treated with blank medium (model group) or blank nanoemulsion in medium (drug-free NE group, $10 \mu \mathrm{mol} / \mathrm{L}$ and $0.1 \mu \mathrm{mol} / \mathrm{L}$ ) for 6 hours before exposed to $30 \mathrm{mmol} / \mathrm{L} \mathrm{L}-\mathrm{Glu}$ for another 6 hours. The control group was cultured with blank medium only. MTT assay was used to detect cell viability.

Then, the effects of OST-NE in L-Glu-induced SHSY5Y cells were investigated. SH-SY5Y cells were seeded in 96-well culture plates $\left(2 \times 10^{4}\right.$ cells, $100 \mu \mathrm{L}$ per well). After 24 hours of incubation, blank nanoemulsion 
(model), OST-NE $(10 \mu \mathrm{mol} / \mathrm{L}$ and $0.1 \mu \mathrm{mol} / \mathrm{L})$ were added and incubated for 6 hours. The culture medium was replaced by $30 \mathrm{mmol} / \mathrm{L} \mathrm{L-Glu}$ in medium and incubated for 6 hours. The control group was cultured with blank nanoemulsion for 6 hours and then blank medium for 6 hours, respectively. MTT assay was used to detect cell viability.

2.9. Cell Viability Assay. The MTT assay was implemented as previously described [7]. After the aforementioned treatments, $20 \mu \mathrm{L}$ of MTT solution $(5 \mathrm{mg} / \mathrm{mL}$, KeyGEN BioTECH, Nanjing, China) was added to each well, and the plate was incubated at $37^{\circ} \mathrm{C}$ for 4 hours. The supernatant was discarded, $150 \mu \mathrm{L}$ of dimethyl sulfoxide was added to dissolve the formazan crystals, and the optical density (OD) was determined using a microplate reader (TECAN, Switzerland) at $570 \mathrm{~nm}$ [28]. The cell viability for each group was calculated by cell viability $(\%)=\mathrm{OD}_{\text {experiment }} / \mathrm{OD}_{\text {control }} * 100$.

2.10. Terminal Deoxynucleotidyl Transferase- (TdT-) Mediated Deoxyuride-Triphosphate- (dUTP-) Biotin NickEnd Labeling (TUNEL) Staining. Apoptotic cells were detected by using the In Situ Cell Death Detection Kit (Roche) based on TUNEL technology. After OST-NE/L-Glu treatment, SH-SY5Y cells were fixed with $4 \%$ paraformaldehyde for 10 minutes and penetrated with $0.1 \%$ Triton $\mathrm{X}$ 100 for 1 minute at room temperature. The TdT and dUTP mixtures were added to the cells and incubated for 2 hours at $37^{\circ} \mathrm{C}$. After three washes with phosphate-buffered saline, the cells were incubated with 4,6-diamino-2-phenylindole (DAPI) for 10 minutes at room temperature [11]. A fluorescence microscope (NIKON ECLIPSE C1, Japan) was used to capture images.

2.11. Biochemical Detection. Superoxide dismutase (SOD), malonaldehyde (MDA), glutathione (GSH), glutathione peroxidase (GSH-Px), and acetylcholine (Ach) (all kits were from Nanjing Jiancheng Bioengineering Institute, Nanjing, China) were measured according to the manufacturer's instructions. The activity of acetylcholinesterase (AchE) was detected according to the instructions of the enzyme-linked immunosorbent assay kit (Elabscience Biotechnology Co., Ltd., Wuhan, China). A microplate reader (TECAN, Switzerland) was used to detect the OD.

2.12. Western Blot Analysis. After treatment with or without OST-NE/L-Glu as described, SH-SY5Y cells from each group were collected, respectively. Total proteins were extracted with protein lysis buffer, and protein concentrations were determined using a BCA protein assay kit (Solarbio Life Sciences, Beijing, China). Proteins were separated by sodium dodecyl sulfate-polyacrylamide gel electrophoresis and transferred onto polyvinylidene fluoride membranes. After being blocked with $5 \%$ skim milk in tris-buffered saline containing $0.1 \%$ Tween-20 (TBST) for 1 hour, the membranes were incubated with primary antibodies at $4^{\circ} \mathrm{C}$ overnight: rabbit polyclonal anti-caspase-3 (1:500) (Servicebio, Wuhan, China), rabbit polyclonal anti-Bax $(1: 800)$ (Servicebio, Wuhan, China), and mouse polyclonal anti- $\beta$-actin ( $1: 1000)$ (ZSGB-BIO, Beijing, China). Then, the membranes were washed three times with TBST, followed by incubating with horseradish peroxidase-conjugated anti-rabbit/mouse immunoglobulin G (IgG) antibody (ZSGB-BIO, Beijing, China) for 2 hours at room temperature. After three washes in TBST, the membranes were added with chemiluminescence solution and visualized via a gel imaging system. The images were analyzed using ImageJ software.

2.13. Learning and Memory Tests. Kunming mice (8-monthold) were randomly divided into five groups: vehicle, scopolamine, OST-NE $(0.1 \mathrm{mg} / \mathrm{kg})$, OST $(25 \mathrm{mg} / \mathrm{kg})$, and drug-free NE groups. The OST-NE $(0.1 \mathrm{mg} / \mathrm{kg})$ group was administered via IN, whereas the OST $(25 \mathrm{mg} / \mathrm{kg})$ group was administered intragastrically. The vehicle and scopolamine groups received the same amount of $0.9 \%$ saline intragastrically. The drug-free NE group received the same amount of blank nanoemulsion via IN. The frequency of administration was once daily for 21 days. On the 21 st day, mice were intraperitoneally injected with $3 \mathrm{mg} / \mathrm{kg}$ scopolamine hydrobromide (Aladdin, Shanghai, China) 30 minutes after administration. Then, Morris water maze and light-dark box tests were performed according to our previous study [29]. Twelve hours after the behavioral experiments, blood was collected through the eyeball. The mice were euthanized and decapitated, and brain tissues were collected.

2.14. Statistical Analysis. The data are presented as the mean \pm standard deviation (SD). The statistical analyses were performed using GraphPad Prism 6 software. Differences were analyzed using one-way analysis of variance (ANOVA). A $P$ value less than 0.05 was defined as statistical significance.

\section{Results}

3.1. Solubilities of OST in Different Surfactants and Cosurfactants. Figure 1 shows the solubilities of OST in different surfactants and cosurfactants. The solubility of OST in ethyl oleate $(37.03 \pm 1.2 \mathrm{mg} / \mathrm{mL})$ was higher than that in isopropyl myristate $(27.1 \pm 0.1 \mathrm{mg} / \mathrm{mL})$. OST exhibited higher solubility in surfactants than in oils: HS-15 $(180.6 \pm 1.1 \mathrm{mg} / \mathrm{mL})$, EL-35 $(157.39 \pm 7.6 \mathrm{mg} / \mathrm{mL})$, Tween$80 \quad(171.88 \pm 8.1 \mathrm{mg} / \mathrm{mL})$, and HS-15 and EL-35 $(169.69 \pm 8.1 \mathrm{mg} / \mathrm{mL})$. In cosurfactants, the solubilities were $121.8 \pm 8.9 \mathrm{mg} / \mathrm{mL}, 71.1 \pm 5.8 \mathrm{mg} / \mathrm{mL}$, and $9.8 \pm 0.9 \mathrm{mg} / \mathrm{mL}$ in PEG400, absolute ethanol, and 1,2-propanediol, respectively.

3.2. Lipid-Water Partition Coefficient of OST. The concentrations of the two phases determined by HPLC were $C_{\text {oil }}=2.4$ $\mathrm{mg} / \mathrm{mL}$ and $C_{\text {water }}=1.4 \mu \mathrm{g} / \mathrm{mL}$, respectively. According to formula (1), $\log P$ was calculated to be 3.23 .

3.3. Pseudoternary Phase Diagrams. The pseudoternary phase diagrams of different surfactants are shown in Figure 2. The shaded area was the largest when the surfactant was a mixture of HS-15 and EL-35 at a ratio of $1: 1$ and $\mathrm{Km}=4: 1$ (Figure 2(c)).

3.4. Characteristics of OST-NE. The stability determination showed that the OST-NE was a clear, transparent, blue 


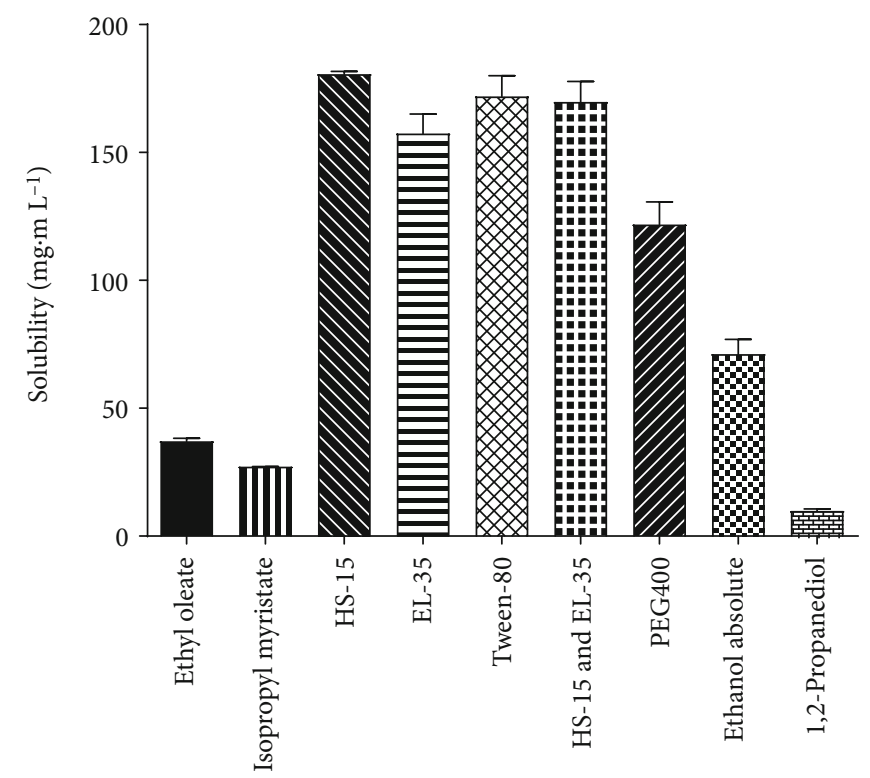

FIgURE 1: Solubility of OST in different surfactants and cosurfactants.

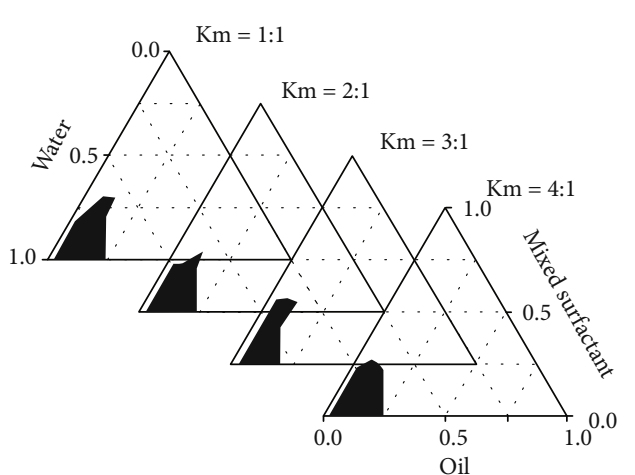

(a)

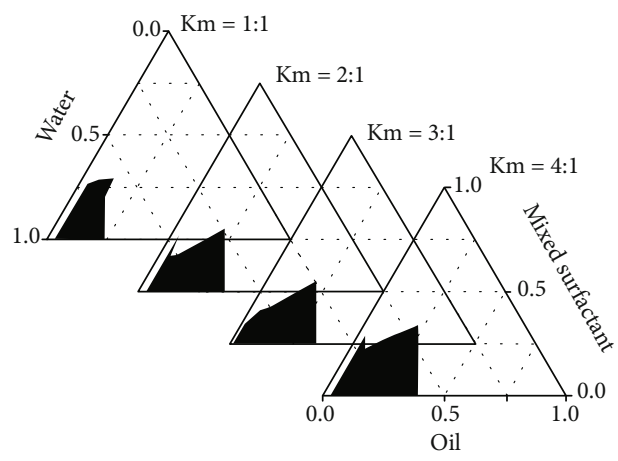

(c)

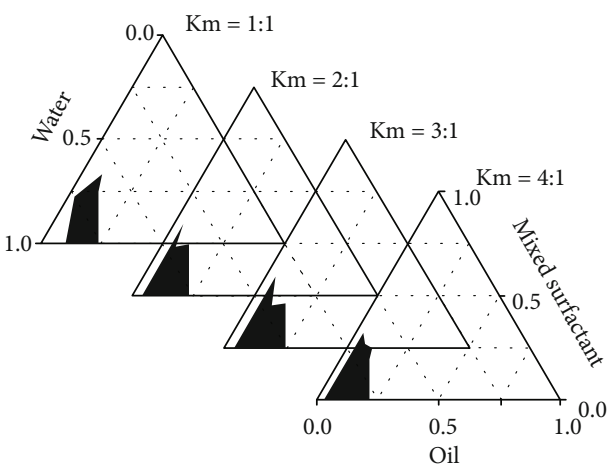

(b)

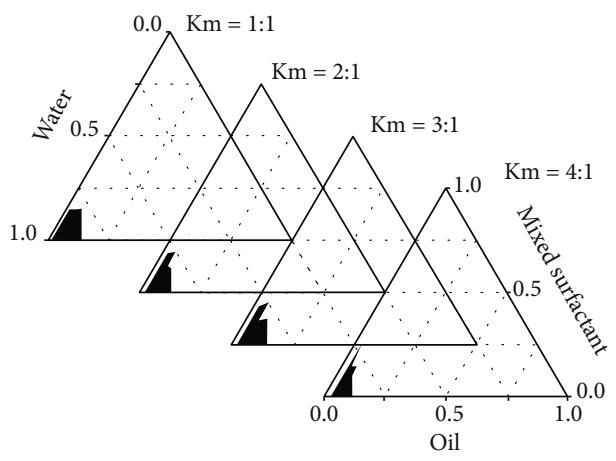

(d)

Figure 2: Pseudoternary phase diagrams of the oil-surfactant-water systems. The shaded region represents nanoemulsion. (a) EL-35 as surfactant; (b) HS-15 as surfactant; (c) a mixture of EL-35 and HS-15 at a ratio of 1:1 as surfactant; (d) Tween-80 as surfactant.

opalescent liquid with a slight odor before high-speed centrifugation. After centrifugation, the nanoemulsion was a light blue transparent liquid without delamination, turbidity, and precipitation. The average particle size of the OST-NE was $22.33 \pm 0.47 \mathrm{~nm}$, and the PDI was $0.115 \pm 0.057$ (Figure 3(a)). The particle size of OST-NE was small and uni- form. The zeta potential of OST-NE was $-9.88 \pm 0.64 \mathrm{mv}$ (Figure 3(b)). A type identification test showed that the diffusion rate of water-soluble dye methylene blue was faster than that of oil dye Sudan Red III (Figure 3(c)). The OST-NE particles were round in shape with a uniform size and good dispersion (Figure 3(d)). 


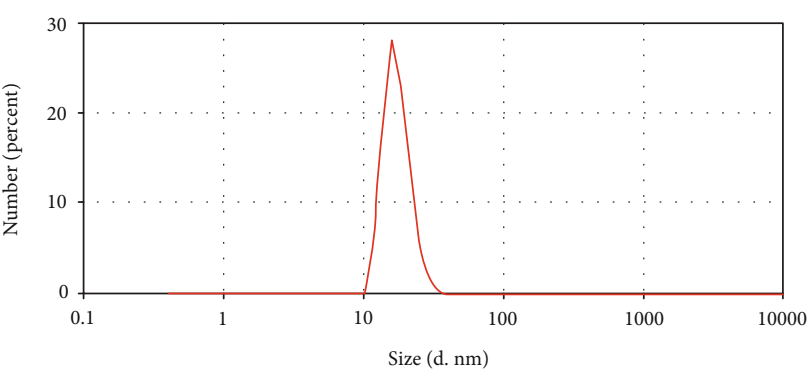

(a)

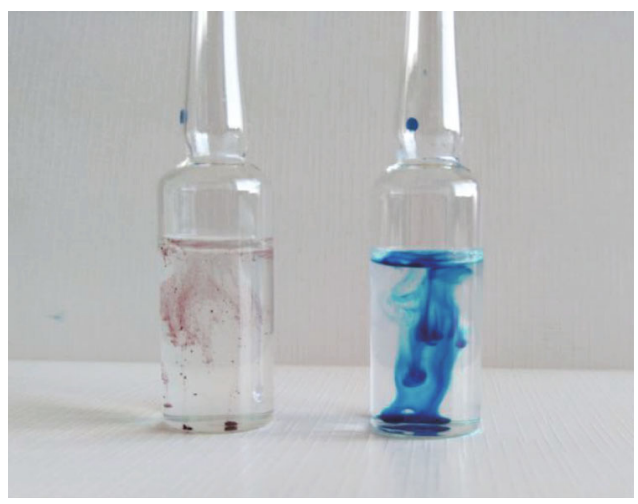

(c)

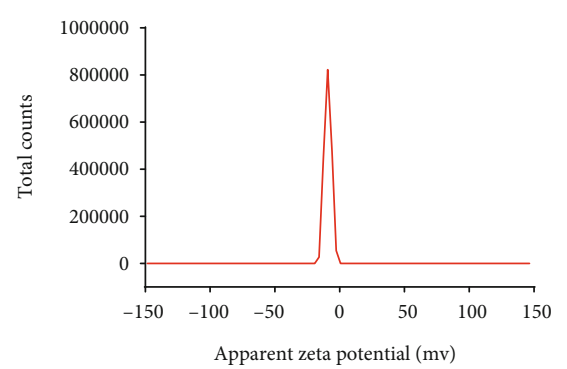

(b)

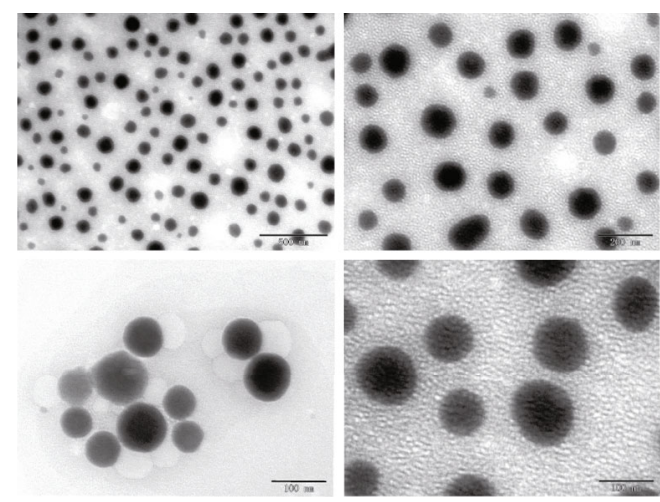

(d)

Figure 3: Characteristics of OST-NE. (a) Particle size of OST-NE. (b) Zeta potential of OST-NE. (c) The different diffusion velocity of oil dye Sudan Red III (left) and water-soluble dye methylene blue (right) in the OST-NE. (d) TEM images of OST-NE, scale bars = 500 nm (top left), $200 \mathrm{~nm}$ (top right), and $100 \mathrm{~nm}$ (bottom).

3.5. Stability of OST-NE. As shown in Table 1, the particle size, PDI, and zeta potential of the OST-NE changed only slightly during storage, indicating that the prepared OSTNE had good thermodynamic stability.

3.6. In Vitro Release. The drug content of OST-NE in the dialysis bag was $4 \mathrm{mg}$, which was released in $200 \mathrm{~mL}$ of SNES release medium. The release of OST was increased in a time-dependent manner within 72 hours. However, the OST-NE released more OST than OST suspensions. By 72 hours, the OST-NE released approximately $80 \%$ of OST, whereas the OST suspensions only released about $40 \%$ of OST (Figure 4), indicating that the release rate of OST-NE in the body was relatively high. According to the principles of kinetics, the correlation between the cumulative release of OST and time was analyzed. Table 2 shows the model fitting for the in vitro release profile of OST. The optimal mathematical model of the drug release process was explored by the value of the correlation coefficient $r$ of the equation. The in vitro drug release process of OST-NE in SNES containing $1 \%$ Tween-80 conformed to the first-order kinetic model, and the OST suspension conformed to the Higuchi model.

3.7. Pharmacokinetic Profile. In plasma, the OST concentration reached the maximum just 5 minutes after administration by the IV route, whereas it took 30 minutes to reach the maximum concentration by the IN route (Figure 5). Moreover, the maximum concentration of OST in plasma by the IN route $(3.53 \pm 0.67 \mu \mathrm{g} / \mathrm{mL})$ was lower than that by the IV route $(9.63 \pm 1.44 \mu \mathrm{g} / \mathrm{mL})$. For $\mathrm{AUC}_{0-t}$ and $\mathrm{AUC}_{0-\infty}$ , there was no significant difference between IV and IN administration. The clearance rate by the IV route was 1.79 times higher than that of IN administration (Table 3).

In the brain, the maximum concentration of OST by IN $(33.04 \pm 2.56 \mu \mathrm{g} / \mathrm{mL}, 5$ minutes after administration) was higher than that by IV $(25.62 \pm 1.86 \mu \mathrm{g} / \mathrm{mL}, 30$ minutes after administration) (Figure 5 and Table 3). The $\mathrm{AUC}_{0-t}$ and $\mathrm{AUC}_{0-\infty}$ of OST by IN were 0.61 times and 0.63 times higher than that of IV administration, respectively. The clearance rate by IV was 7.08 times higher than that of IN administration (Table 4).

The $\mathrm{AUC}_{\text {brain }} / \mathrm{AUC}_{\text {plasma }}$ values after IV and IN administrations of OST-NE were 2.82 and 4.88, respectively. The DTE\% and DTP\% of OST-NE after IN administration were $207.27 \%$ and $51.80 \%$, respectively.

3.8. Sterilization Method of OST-NE. The OST-NE was layered after high temperature autoclaving (Figure 6(c)). Bacteria were still detectable in the OST-NE after 2 hours of UV irradiation, whereas no bacterium was detected by using a microporous membrane to sterilize. Therefore, the microporous membrane was used to filter the OST-NE.

3.9. Effects of OST-NE on the Activity of SH-SY5Y Cells. The neuroblastoma SH-SY5Y cell line is frequently chosen as a neuronal cell model in neurobiology [30-32]. In this study, SH-SY5Y cells were used to mimic AD as a cellular model 
TABLE 1: Average particle size, PDI, and absolute zeta potential of OST-NE during storage.

\begin{tabular}{lccc}
\hline Time (days) & Particle size $(\mathrm{nm})$ & PDI & Zeta $(\mathrm{mv})$ \\
\hline 0 & $21.09 \pm 0.06$ & $0.053 \pm 0.013$ & $-7.24 \pm 1.85$ \\
5 & $21.22 \pm 0.23$ & $0.068 \pm 0.014$ & $-6.45 \pm 1.90$ \\
10 & $21.61 \pm 0.42$ & $0.145 \pm 0.032$ & $-8.69 \pm 2.12$ \\
15 & $21.12 \pm 0.11$ & $0.081 \pm 0.006$ & $-6.30 \pm 3.66$ \\
20 & $20.96 \pm 0.23$ & $0.063 \pm 0.002$ & $-4.04 \pm 1.10$ \\
25 & $22.16 \pm 0.28$ & $0.136 \pm 0.015$ & $-4.81 \pm 1.06$ \\
\hline
\end{tabular}

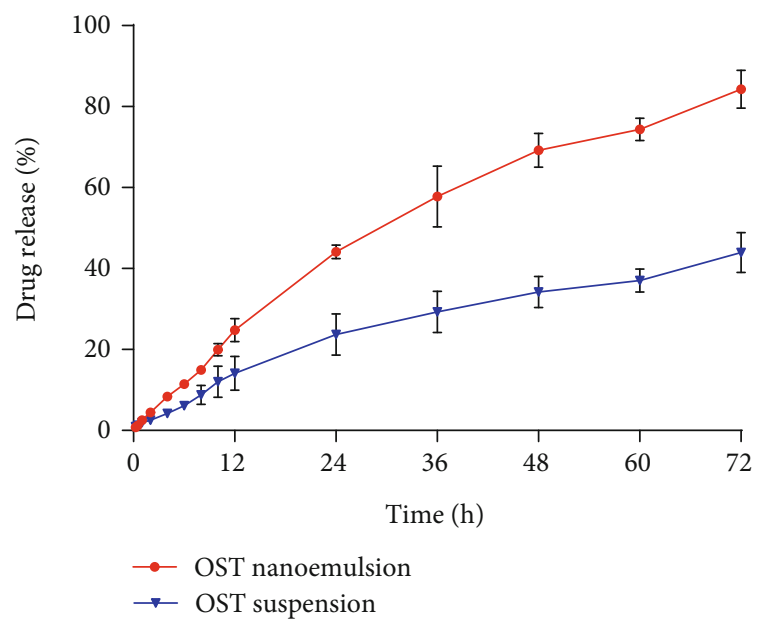

FIGURE 4: In vitro release of OST from nanoemulsion compared with suspension.

and to assess whether OST-NE had a protective effect in this AD cellular model. To ensure the safety of OST-NE to the SH-SY5Y cells, the effects of OST-NE at different concentrations on the activity of SH-SY5Y cells were investigated. OST-NE at the concentration of 100,50 , and $25 \mu \mathrm{mol} / \mathrm{L}$ significantly inhibited the viability of SH-SY5Y cells $(19.97 \pm 2.88 \%, 35.78 \pm 4.72 \%$, and $81.85 \pm 12.09 \%$, respectively), indicating that OST-NE at the concentration of over $25 \mu \mathrm{mol} / \mathrm{L}$ was harmful to SH-SY5Y cells. While treated with 10 and $0.1 \mu \mathrm{mol} / \mathrm{L}$ OST-NE, the cell viability changed insignificantly compared with the control group (Figure 7(a)), suggesting that 10 and $0.1 \mu \mathrm{mol} / \mathrm{L}$ of OST-NE were safe for SH-SY5Y cells.

3.10. Effects of OST-NE on Cell Viability in L-Glu-Induced SH-SY5Y Cells. Glutamate overstimulation is associated with neuronal cell death [33] and may underlie the pathogenic mechanisms of AD [34]. L-Glu inhibited SH-SY5Y cells in a concentration-dependent manner in this study. The cell viability was decreased to $50 \%$ following incubation of LGlu at $30 \mathrm{mmol} / \mathrm{L}$ for 6 hours (Figure 7(b)). Compared with the control group, the cell viability in the L-Glu group was significantly decreased $(P<0.01)$ (Figures $7(\mathrm{c})$ and $7(\mathrm{~d})$ ). After pretreating with blank nanoemulsion at 10 or $0.1 \mu \mathrm{mol} / \mathrm{L}$, the cell viability was altered insignificantly com- pared with the L-Glu group (Figure 7(c)). OST-NE of both doses $(10$ and $0.1 \mu \mathrm{mol} / \mathrm{L})$ increased the cell viability significantly compared with the L-Glu group $(P<0.01)$ (Figure $7(\mathrm{~d})$ ), suggesting that OST-NE had a protective effect.

3.11. OST-NE Protects SH-SY5Y Cells against L-Glu-Induced Apoptosis. TUNEL staining detects DNA damage by labeling the free $3^{\prime}$-hydroxyl termini [35]. During the early and late stages of apoptosis, genomic DNA breaks arise. So TUNEL staining is widely used as a measure of apoptosis, and TUNEL-positive cells are a specific parameter that indicates the apoptotic cells [36]. As shown in Figure 8, L-Glu treatment significantly increased the number of TUNEL-positive cells (red fluorescence-labeled cells) as compared with control SH-SY5Y cells, indicating that L-Glu $(30 \mathrm{mmol} / \mathrm{L})$ promoted the apoptosis of SH-SY5Y cells. Compared with the L-Glu group, the number of TUNEL-positive cells was decreased in the OST-NE pretreatment group, suggesting that OST-NE protected SH-SY5Y cells against L-Gluinduced apoptosis.

3.12. OST-NE Regulates Apoptosis-Related Proteins in L-GluInduced SH-SY5Y Cells. Bax and caspase-3 play important roles in the mechanisms of cell death in $\mathrm{AD}$ [37-39]. Bax is a proapoptotic effector [40], and caspase- 3 is responsible for killing the cells at the end of the caspase cascades and mediates apoptosis [41]. L-Glu treatment significantly increased the relative expression of Bax and caspase- 3 protein when compared with the control group $(P<0.05)$ (Figure 9). The relative expression of Bax and caspase-3 protein in the OST-NE pretreated group was lower than that in the L-Glu treated group $(P<0.05)$ (Figure 9$)$, indicating that OST-NE inhibited the protein expression of Bax and caspase3 induced by L-Glu.

3.13. OST-NE Increases Antioxidant Enzyme Activity in LGlu-Induced SH-SY5Y Cells. Free radical-mediated oxidative damage may trigger the apoptosis and is also involved in the pathogenesis of $\mathrm{AD}$ [42]. Antioxidants are capable of inhibiting the radical chain reaction. Hence, they have great potential in the prevention and treatment of AD. SOD and GSH are two important endogenous antioxidants [43]. Figure 10 shows the activities of SOD and GSH in different groups. Both SOD and GSH activities were decreased in SH-SY5Y cells exposed to L-Glu compared with those of the control (both $P<0.05)$. OST-NE $(0.1 \mu \mathrm{mol} / \mathrm{L}) \quad$ pretreatment increased the SOD and GSH activities significantly (both $P$ $<0.01)$. OST-NE $(10 \mu \mathrm{mol} / \mathrm{L})$ pretreatment also significantly increased the SOD activity $(P<0.01)$ and showed a trend to increase the GSH activity. These results indicate that OSTNE had antioxidative effects.

3.14. OST-NE Improves Learning and Memory Ability in Scopolamine-Induced $A D$ Mice. In the Morris water maze test, the number of platform crossing in the scopolamine group was significantly decreased compared with the vehicle group $(P<0.05)$ (Figure 11(a)). The OST-NE group $(0.1 \mathrm{mg} / \mathrm{kg})$ and the OST group $(25 \mathrm{mg} / \mathrm{kg})$ showed higher number in crossing the platform than the scopolamine group. In the light-dark test, after a single electric shock 
TABLE 2: Model fitting for in vitro release profile of OST.

\begin{tabular}{lcccc}
\hline Model & Osthole nanoemulsion & $r$ & Osthole suspension & $r$ \\
\hline Zero-order & $Q=1.2205 t+5.1462$ & 0.9831 & $Q=0.6085 t+3.3968$ & 0.9804 \\
First-order & $\operatorname{Ln}(100-Q)=-0.0247 t+4.6188$ & 0.9978 & $\operatorname{Ln}(100-Q)=-0.0079 t+4.5777$ \\
Higuchi & $Q=11.084 t^{1 / 2}-10.955$ & 0.9928 & $Q=5.544 t^{1 / 2}-4.6974$ & 0.9904 \\
\hline
\end{tabular}

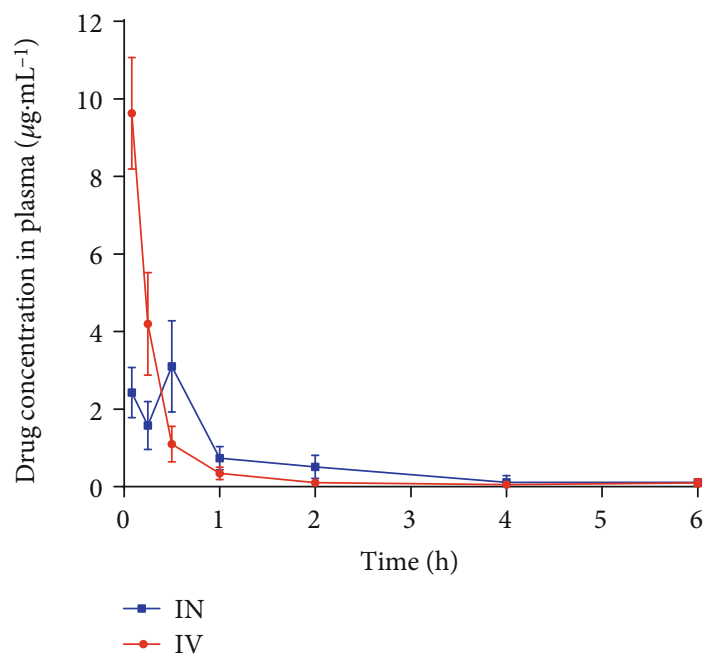

(a)

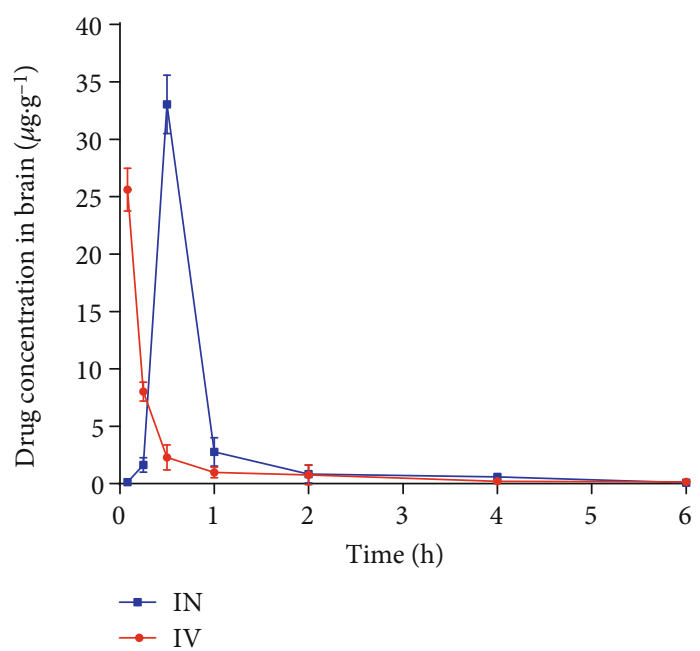

(b)

FIGURE 5: Pharmacokinetics curve of OST-NE in plasma and brain tissue after IN and IV administrations: (a) drug concentration in plasma; (b) drug concentration in the brain.

TABLE 3: Pharmacokinetic parameters of OST-NE in plasma after IN and IV administrations.

\begin{tabular}{lcccrr}
\hline Parameters & $C_{\max }(\mu \mathrm{g} / \mathrm{mL})$ & $\mathrm{AUC}_{0-t}(\mu \mathrm{g} / \mathrm{mL} * \mathrm{~h})$ & $\mathrm{AUC}_{0-\infty}(\mu \mathrm{g} / \mathrm{mL} * \mathrm{~h})$ & $\mathrm{CL}(\mathrm{l} / \mathrm{H} / \mathrm{kg})$ & $\mathrm{MRT}_{0-t}(\mathrm{~h})$ \\
\hline Intranasal & $3.53 \pm 0.67$ & $2.90 \pm 0.18$ & $2.93 \pm 0.22$ & $2.86 \pm 1.04$ & $1.23 \pm 0.30$ \\
Intravenous & $9.63 \pm 1.44$ & $3.70 \pm 0.51$ & $3.74 \pm 0.53$ & $7.99 \pm 0.69$ & $0.52 \pm 0.22$ \\
\hline
\end{tabular}

Note: $C_{\max }:$ maximum concentration; CL: plasma clearance; MRT: mean residence time.

TABle 4: Pharmacokinetic parameters of OST-NE in the brain after IN and IV administrations.

\begin{tabular}{lcccrr}
\hline Parameters & $C_{\max }(\mu \mathrm{g} / \mathrm{mL})$ & $\mathrm{AUC}_{0-t}(\mu \mathrm{g} / \mathrm{mL} * \mathrm{~h})$ & $\mathrm{AUC}_{0-\infty}(\mu \mathrm{g} / \mathrm{mL} * \mathrm{~h})$ & $\mathrm{CL}(\mathrm{l} / \mathrm{H} / \mathrm{kg})$ & $\mathrm{MRT}_{0-t}(\mathrm{~h})$ \\
\hline Intranasal & $33.04 \pm 2.56$ & $16.87 \pm 2.35$ & $17.55 \pm 2.48$ & $0.36 \pm 0.23$ & $0.82 \pm 0.14$ \\
Intravenous & $25.62 \pm 1.86$ & $10.45 \pm 2.69$ & $10.80 \pm 2.72$ & $2.91 \pm 0.54$ & $0.47 \pm 0.24$ \\
\hline
\end{tabular}

training, the scopolamine group had the shortest stepthrough latency, indicating that the $\mathrm{AD}$ mouse model was successfully prepared. Compared with the scopolamine group, the step-through latency had a trend to be increased by IN administration of OST-NE $(0.1 \mathrm{mg} / \mathrm{kg})$ (Figure 11(b)). The difference between the drug-free NE group and the scopolamine group did not achieve statistical significance, suggesting that drug-free NE had little influence on the learning and memory ability.

3.15. OST-NE Regulates Oxidative Stress in ScopolamineInduced AD Mice. SOD and GSH-Px are two major antioxidant enzymes, and MDA is an end product of lipid peroxida- tion. Thus, SOD, GSH-Px, and MDA were considered as markers for the evolution of oxidative stress in $\mathrm{AD}[42,44]$. Scopolamine caused a decrease in SOD activity (Figure 11(c)) and GSH-Px content (Figure 11(e)) and an increase in MDA content (Figure 11(d)), indicating that scopolamine induced oxidative damage. The SOD content in the OST-NE group was slightly higher than that in the scopolamine group (Figure 11(c)). The MDA content in the OST$\mathrm{NE}$ group was lower than that in the scopolamine group $(P<0.05)$ (Figure $11(\mathrm{~d}))$. Both OST-NE $(0.1 \mathrm{mg} / \mathrm{kg})$ and OST $(25 \mathrm{mg} / \mathrm{kg})$ increased the GSH-Px content compared with the scopolamine group $(P<0.05)$ (Figure $11(\mathrm{e}))$. SOD, GSH-Px, and MDA were altered very slightly with the 


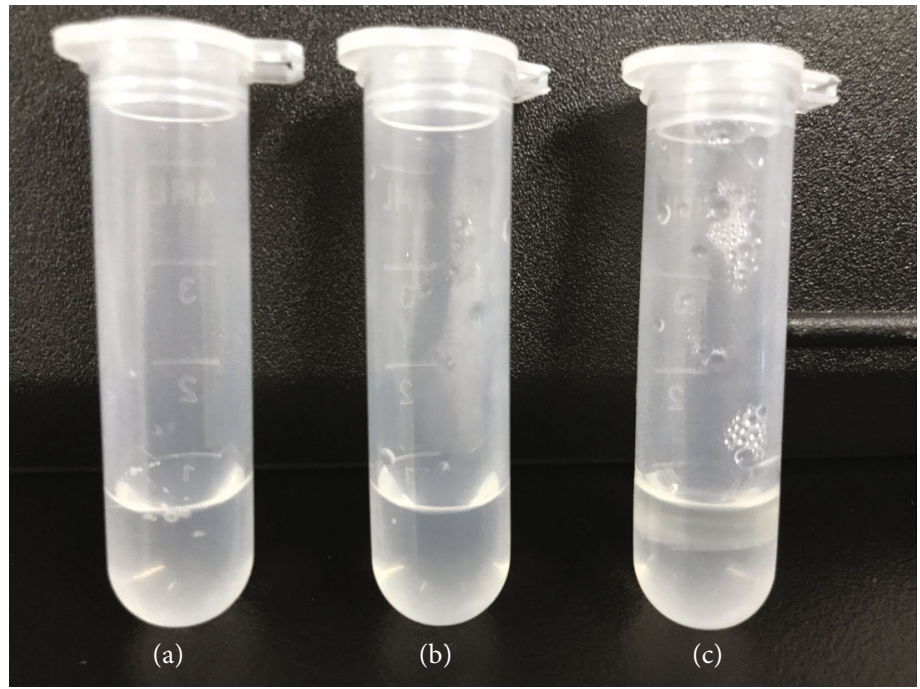

FIGURE 6: Influence of three different sterilization methods on the stability of OST-NE: (a) microporous filter; (b) UV sterilization; (c) autoclave.

treatment of drug-free NE when compared to the scopolamine group, suggesting that drug-free NE modulated the oxidative stress insignificantly.

3.16. OST-NE Regulates Cholinergic Pathway in ScopolamineInduced AD Mice. Dysfunction of the cholinergic system is a key feature of $\mathrm{AD}$, often characterized by altered Ach and AchE [45]. After treating with scopolamine, the Ach concentration in the brains of mice was significantly reduced $(P<0.05)$ (Figure $11(\mathrm{f}))$, whereas the activity of AchE was increased $(P<0.05)$ (Figure $11(\mathrm{~g}))$, suggesting that scopolamine led to cholinergic system impairment. Compared with the scopolamine group, the Ach concentration in the cortex of the OST-NE group and the OST group was increased $(P<0.05)$ (Figure $11(\mathrm{f})$ ), and the AchE activity in the hippocampus of the OST-NE group was significantly decreased $(P<0.05)$ (Figure $11(\mathrm{~g})$ ). There was no significant difference between the drug-free NE group and the scopolamine group. These results indicate that the cholinergic system may be regulated by OST$\mathrm{NE}$, but not by NE alone.

\section{Discussion}

To construct the OST-NE, the solubility of OST in different surfactants and cosurfactants was confirmed first. According to the solubility study, the solubility of OST in ethyl oleate was higher than that in isopropyl myristate (Figure 1). Therefore, ethyl oleate was selected as the oil phase. OST showed relatively high solubility in PEG400; hence, PEG400 was selected as the cosurfactant. In addition to water solubility, an optimal $\log P$ value is required for efficient uptake of a drug by cells [46]. This study showed that $C_{\text {oil }}$ was greater than $C_{\text {water }}$, and the $\log P$ was 3.23 , indicating that OST had higher lipophilicity.

The shaded region in the pseudoternary phase diagram indicates the nanoemulsion domain; the larger the nanoemulsion region is, the stronger the emulsifying ability is
[47]. The present study showed that the largest shaded area was when using a mixture of HS-15 and EL-35 (ratio $1: 1$ ) and when $\mathrm{Km}=4: 1$ (Figure 2(c)). Compared with a single surfactant, the use of surfactant mixtures decreased droplet size and interfacial tension and showed higher storage stability in nanoemulsion [48]. Surfactant mixtures can reduce hydrophilic-lipophilic balance values, which enhances the lipophilic property of the surfactant blend and enhances the flexibility of surfactant layers that were formed [49]. Therefore, $11.4 \%$ of the HS-15 and EL-35 mixture was used as the surfactant, and $3.6 \%$ of ethyl oleate was used as the oil phase in the composition of OSTNE.

This study indicates that the OST-NE had good physical stability. Type identification suggests that the OST-NE was $\mathrm{O} / \mathrm{W}$ type (Figure 3(c)). Smaller droplets have a greater interfacial area that significantly enhances the release rate of the drug [50]. The particle size of OST-NE was small and uniform, with an average particle size of $22.33 \pm 0.47 \mathrm{~nm}$. After being prepared into a nanoemulsion, the dissolution rate of OST can be significantly improved. Therefore, OST-NE released more OST than OST suspensions.

The $\mathrm{AUC}_{\text {brain }} / \mathrm{AUC}_{\text {plasma }}$ ratio represents the brain targeting coefficient of the drug. The $\mathrm{AUC}_{\mathrm{brain}} / \mathrm{AUC}_{\text {plasma }}$ value after IV administration was lower than that by nasal administration of OST-NE. This indicates that OST-NE enhanced brain target by the IN route. The DTP\% was greater than $50 \%$ by IN administration of OST-NE, indicating that half of the OST in the brain tissue entered the brain directly from the nasal cavity. It is known that drug absorption from the nasal cavity to the brain usually occurs through two pathways: (1) systemic pathway: a certain amount of the drug directly enters the systemic circulation and reaches the brain through the BBB; and (2) olfactory pathway: the drug enters the cerebrospinal fluid or brain directly from the nasal cavity [51]. DTE\% and DTP\% correspond to the percentage of drugs that are transported directly to the brain via the olfactory pathway. The higher DTE\% and DTP\% values imply 


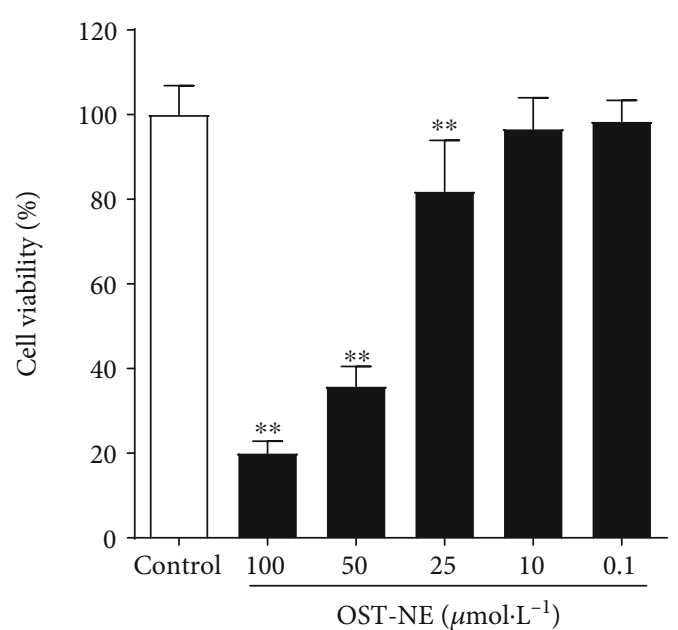

(a)

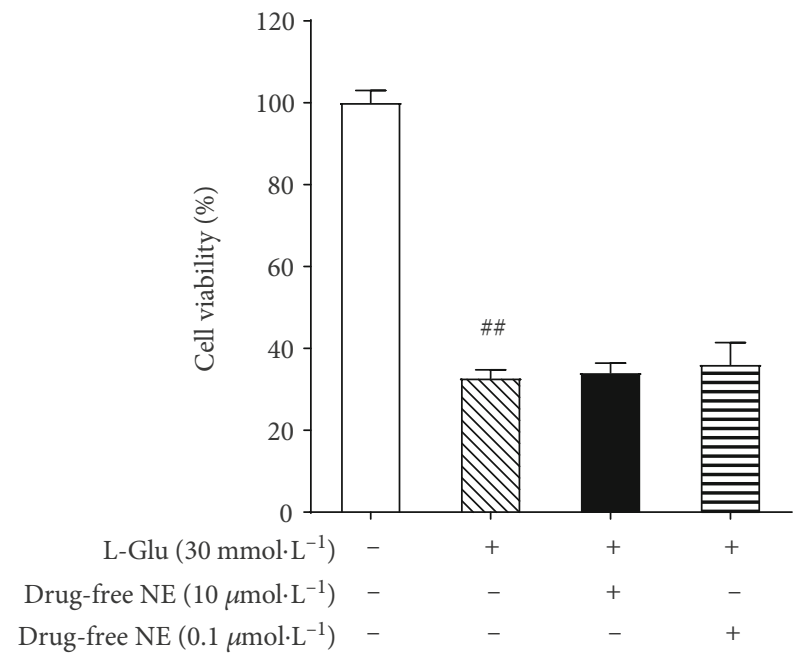

(c)

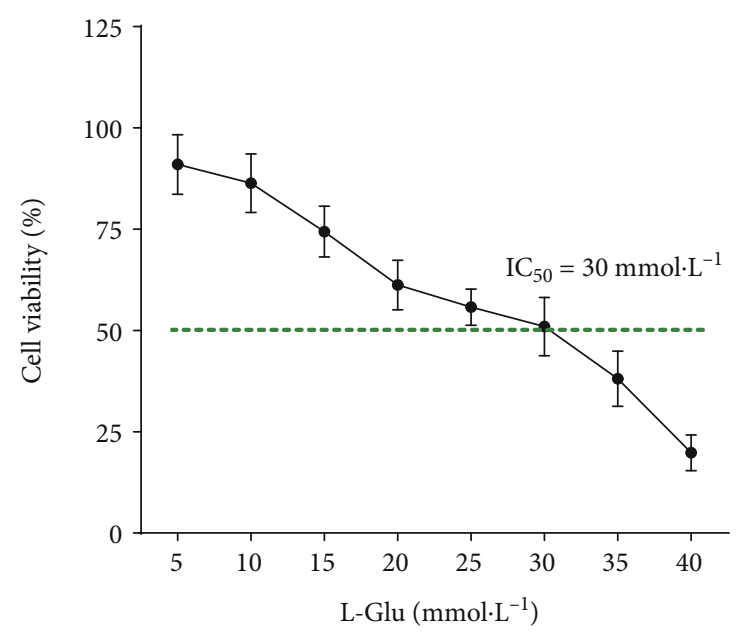

(b)

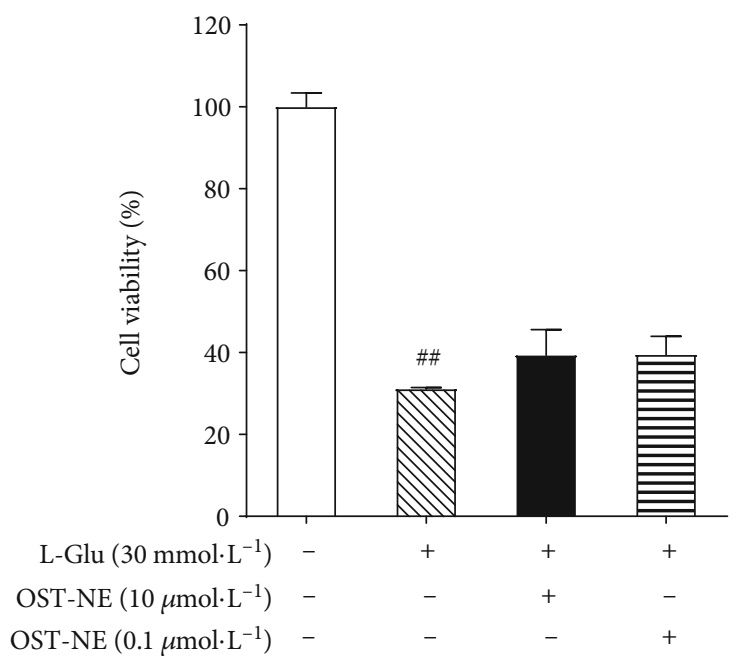

(d)

Figure 7: Effect of OST-NE on cell viability in L-Glu-induced SH-SY5Y cells. (a) Effect of OST-NE on SH-SY5Y cell viability. $n=5-8$ per group, ${ }^{* *} P<0.01$ vs. control group. (b) Effect of L-Glu on the survival of SH-SY5Y cells. (c) Effect of blank nanoemulsion (drug-free NE) on cell viability in L-Glu-induced SH-SY5Y cells. $n=5-8$ per group, ${ }^{\#} P<0.01$ vs. control group. (d) Effect of OST-NE on cell viability in L-Glu-induced SH-SY5Y cells. $n=6-8$ per group, ${ }^{\# \#} P<0.01$ vs. control group, ${ }^{* *} P<0.01$ vs. model group.

that OST-NE had superior brain targeting efficiency. The drug can be quickly transported to the brain by IN administration, which may be due to the smaller particle size with improved transcellular transport [52].

Apoptosis is considered to be an important mechanism of AD [39]. Excessive L-Glu not only results in excitotoxicity but also induces cell death, which may underlie the AD neuropathology [53, 54]. Therefore, the L-Glu-induced cell model was used to investigate the effects of OST-NE on neuronal cell death. Consistent with other study [54], L-Glu at high concentrations significantly increased cell death by using the cell viability test and TUNEL analysis. It has been reported that OST has antiapoptotic activity [7]. In this study, OST-NE also protected the SH-SY5Y cells against apoptosis, suggesting that OST-NE remained the antiapoptosis activity of OST. The apoptosis pathway involves many modulators, including Bax and caspase-3. AD patients exhibited high expression of Bax [55] and an increase in procaspase-3 and active caspase- 3 expression [38], indicating that Bax and caspase- 3 are implicated in AD. Furthermore, Bax promotes the loss of mitochondrial membrane potential and the release of cytochrome $c$ to the cytoplasm, resulting in the subsequent cleavage and activation of the apoptotic caspase-3 [56], suggesting Bax is an upstream modulator that triggers the activation of caspase- 3 and apoptosis. Therefore, to further confirm the antiapoptotic effect of OST-NE, Bax and caspase- 3 were determined. L-Glu increased the expression of Bax and caspase-3, which was consistent with other studies $[57,58]$. OST-NE reversed the increased expression of Bax and caspase- 3 induced by L-Glu. These results suggest that OST may prevent L-Glu-induced apoptosis by regulating apoptotic signals.

Oxidative stress is another key pathogenesis of $\mathrm{AD}$ [43]. Oxidative stress increases neuronal cell damage and 


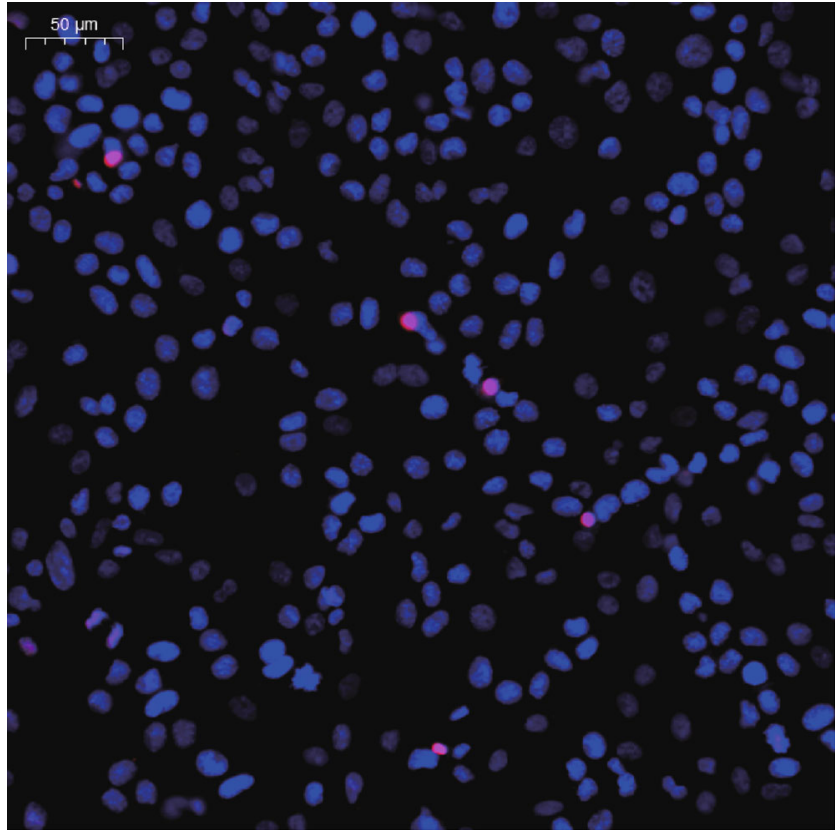

(a)

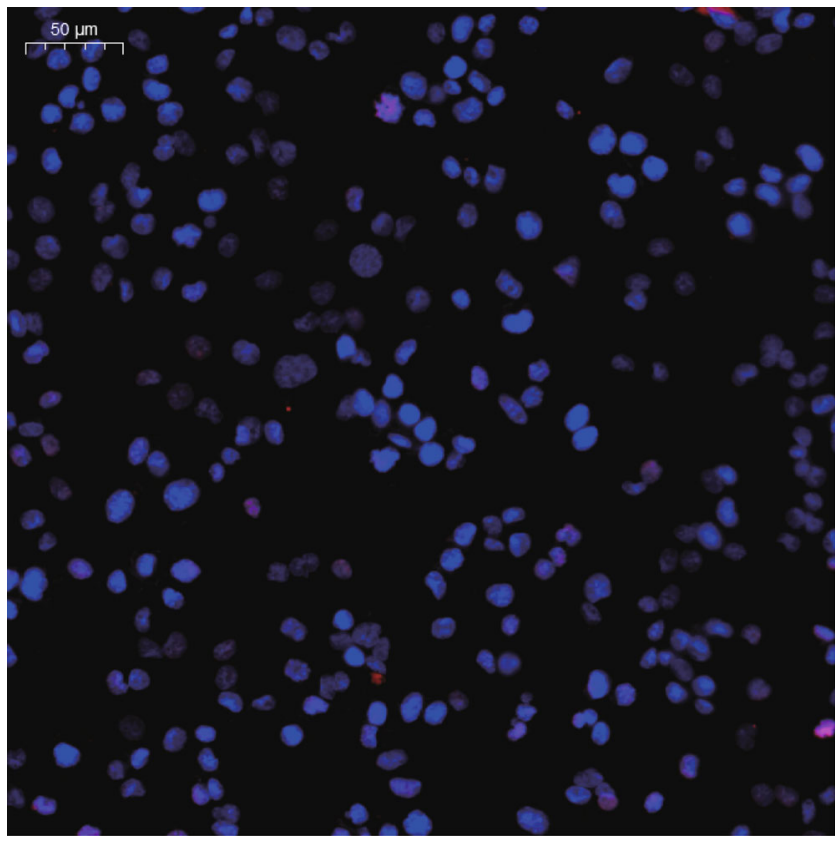

(c)

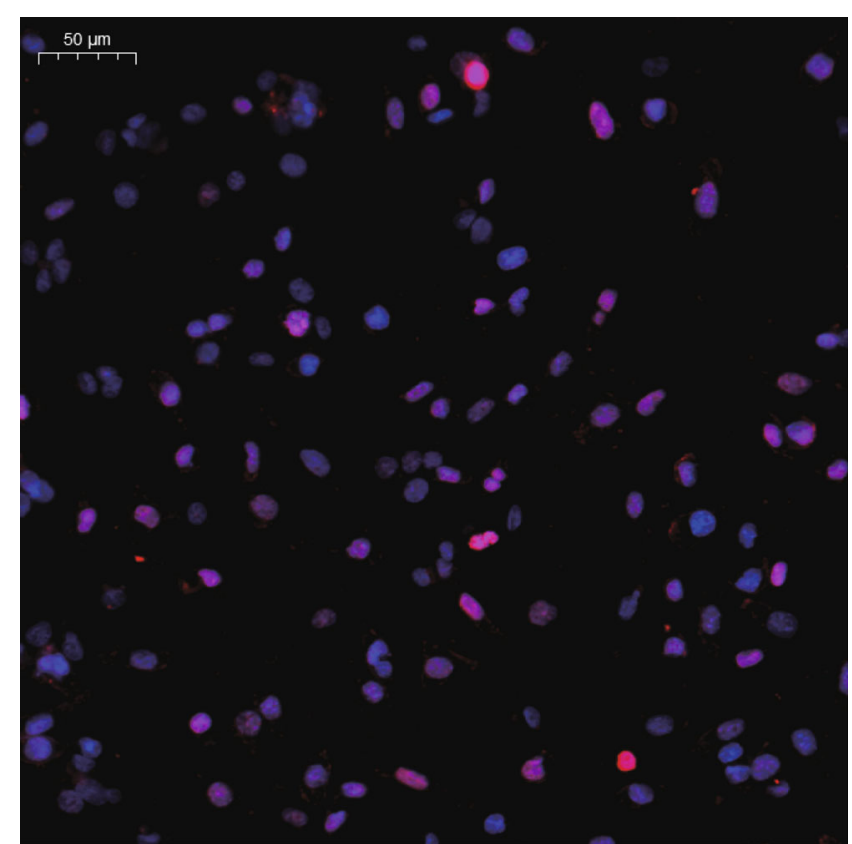

(b)

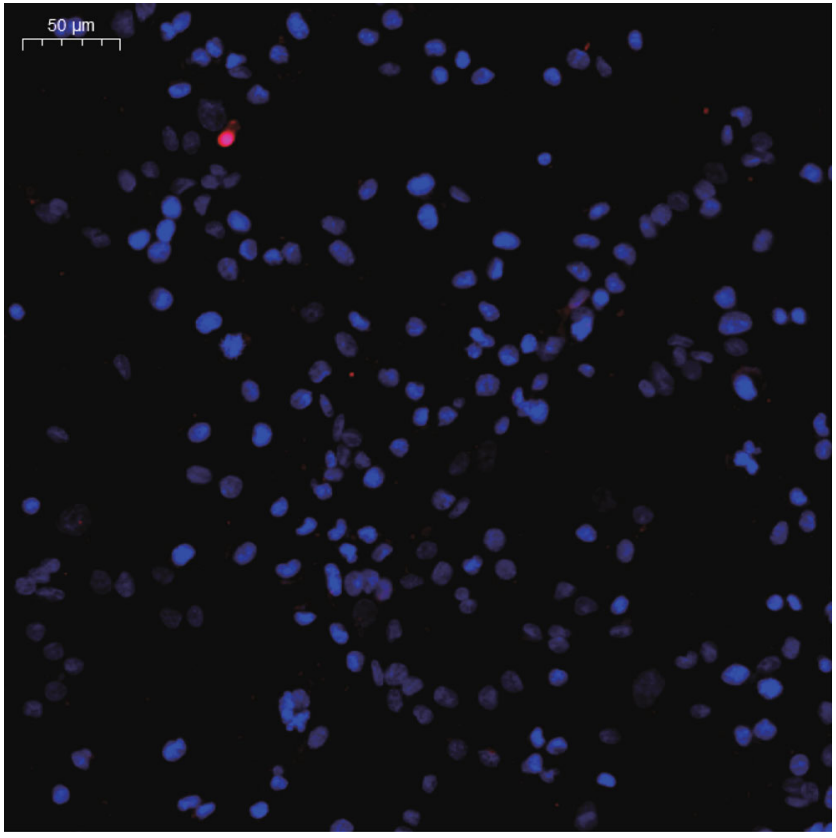

(d)

Figure 8: Effect of OST-NE on L-Glu-induced apoptosis in SH-SY5Y cells by TUNEL staining: (a) control, (b) model (blank nanoemulsion+30 mmol/L L-Glu), (c) OST-NE $(10 \mu \mathrm{mol} / \mathrm{L})+\mathrm{L}-\mathrm{Glu}(30 \mathrm{mmol} / \mathrm{L})$, (d) OST-NE $(0.1 \mu \mathrm{mol} / \mathrm{L})+\mathrm{L}-\mathrm{Glu}(30 \mathrm{mmol} / \mathrm{L})$. Red: TUNEL-positive; blue: DAPI, scale bar $=50 \mu \mathrm{m}$.

apoptosis, leading to cognitive impairment [42]. SOD, GSH, and GSH-Px belong to the antioxidant enzyme system. In $\mathrm{AD}$ patients, the MDA level in the blood was higher along with a decrease in GSH levels, indicating elevated oxidative stress in $\mathrm{AD}$ [59]. SOD is a major component of the antioxidant system and limits the cytotoxic effects of toxic free radicals [60]. Similar to other study [61], L-Glu induced SOD activity reduction. OST-NE pretreatment significantly increased the activity of SOD and GSH, suggesting that
OST-NE may protect SH-SY5Y cells from L-Glu-induced neurotoxicity by reducing oxidative stress. Furthermore, a scopolamine-induced mouse model of AD was employed to confirm the antioxidative effect of OST-NE in vivo, since scopolamine was able to decrease the activity of SOD and increase MDA in the brain [62]. Similar to the in vitro study, OST-NE treatment increased the level of SOD and GSH-Px in the serum. MDA is the final product of lipid peroxidation after biological membranes are attacked by reactive oxygen 


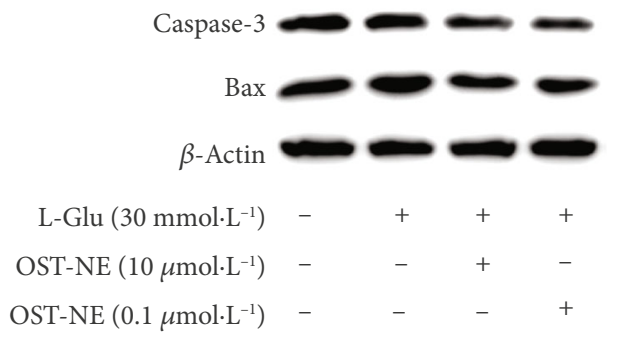

(a)

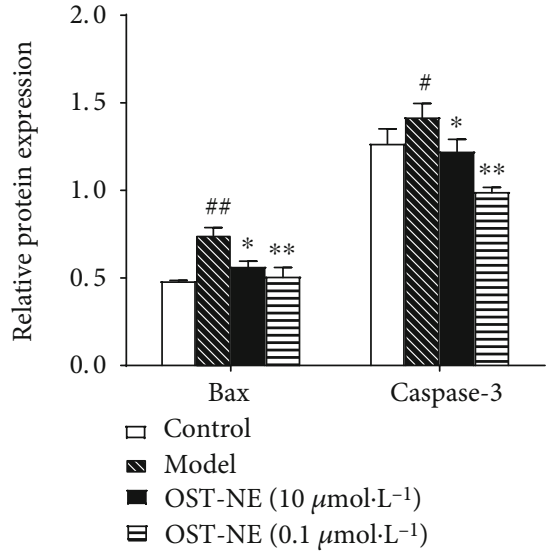

(b)

FIgURE 9: Effects of OST-NE on the protein levels of Bax and caspase-3 in L-Glu-treated SH-SY5Y cells. (a) Representative bands of Bax, caspase-3, and $\beta$-actin by Western blot analysis. (b) Relative protein levels were quantified by densitometry and normalized relative to the expression of $\beta$-actin. $n=3-4$ per group, ${ }^{\# \#} P<0.01$ vs. control group, ${ }^{*} P<0.01$ and ${ }^{* *} P<0.01$ vs. model group.

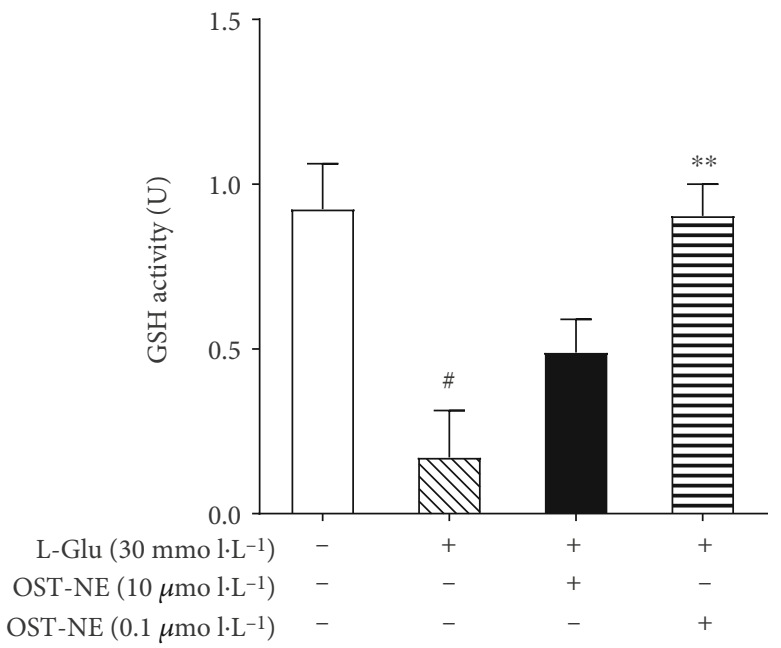

(a)

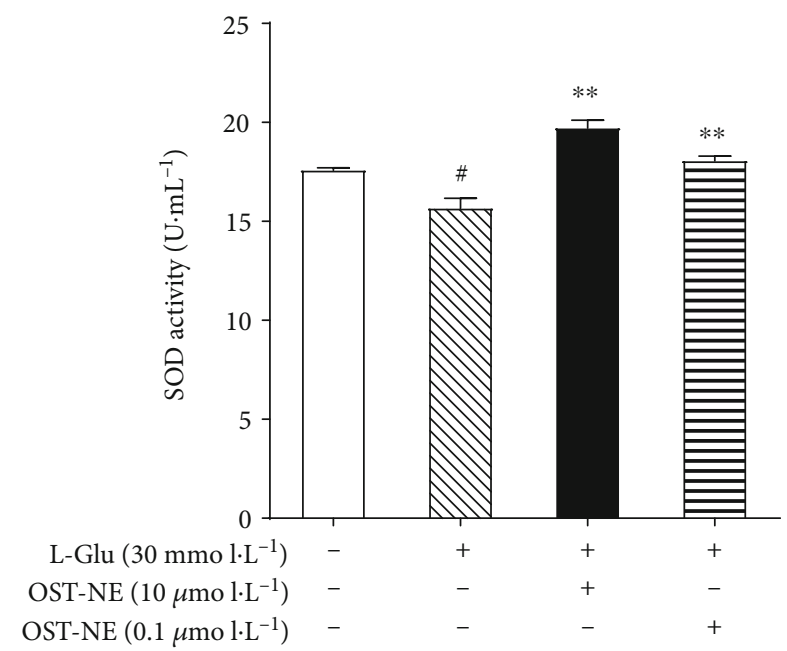

(b)

FIGURE 10: Effect of OST-NE on L-Glu-induced oxidative stress in SH-SY5Y cells. (a) GSH activity, (b) SOD activity. $n=3$ per group, ${ }^{\#} P<0.05$ vs. control group, ${ }^{* *} P<0.01$ vs. model group.

species. The level of MDA can reflect the degree of oxidative stress [63]. This study showed that the MDA level in the serum was significantly decreased in mice treated with OST-NE. Together, these results suggest the antioxidative effect of OST-NE.

Scopolamine not only causes oxidative stress but also impairs the cholinergic function and results in cognition dysfunction [62, 64]. In this study, scopolamine injection also impaired the learning and memory ability, reduced Ach level, and increased the AchE activity in mice. After administration with OST-NE via the nasal route in scopolamine-induced $\mathrm{AD}$ mice, the number of platform crossings was increased, indicating that OST-NE could improve the learning and memory. Cholinergic neurons located in the basal forebrain are severely lost in $\mathrm{AD}$ [65]. Ach is an important neurotransmitter in the central nervous system. Cholinergic neurons release Ach, which is hydrolyzed by the enzyme AchE. Loss of cholinergic neurons leads to reduction in Ach, further resulting in memory impairment in patients with $\mathrm{AD}$ [45]. OST-NE treatment increased the level of Ach and decreased the activity of AchE in the brain in $\mathrm{AD}$ model mice, indicating that OST-NE may be a potential agent for treating $\mathrm{AD}$ by regulating the cholinergic system.

\section{Conclusion}

By using nanoemulsion technology, a formulation of OSTNE was developed and was proved to be well targeted to the brain by the nasal route. Furthermore, OST-NE at a low dose exerts a protective effect on L-Glu-induced neurotoxicity and improves learning and memory in $\mathrm{AD}$ mice, 


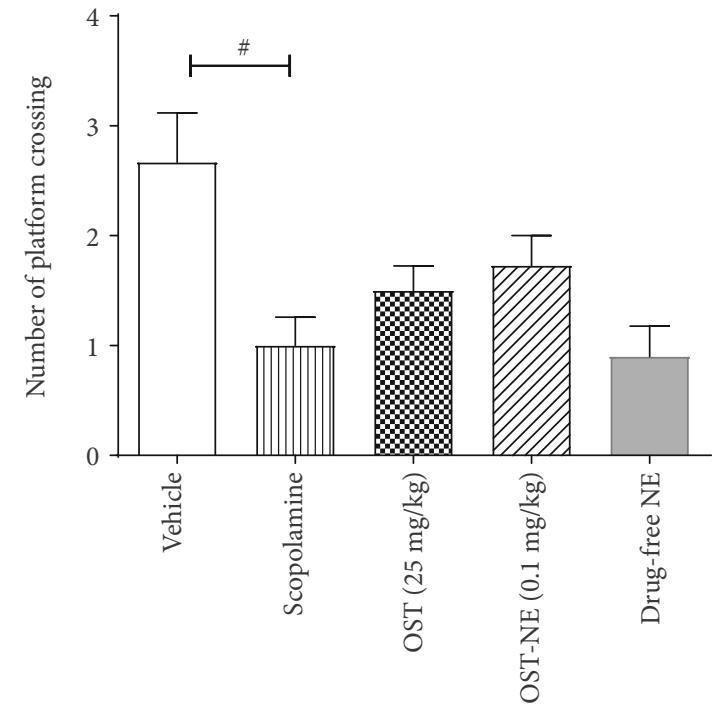

(a)

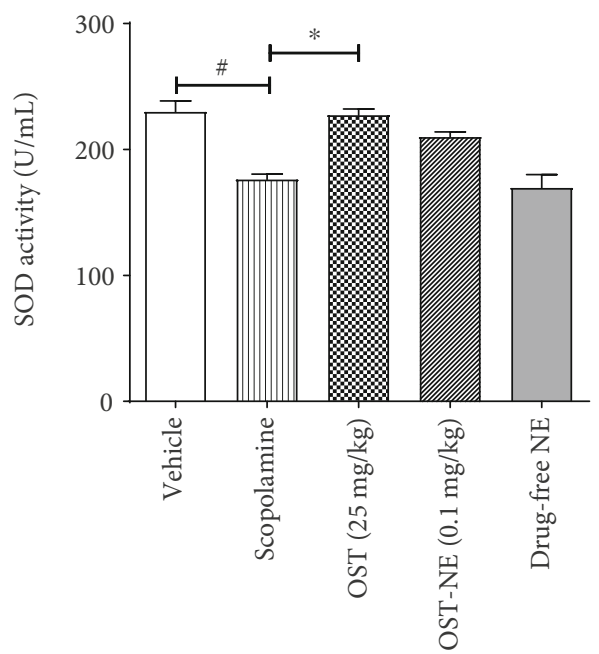

(c)

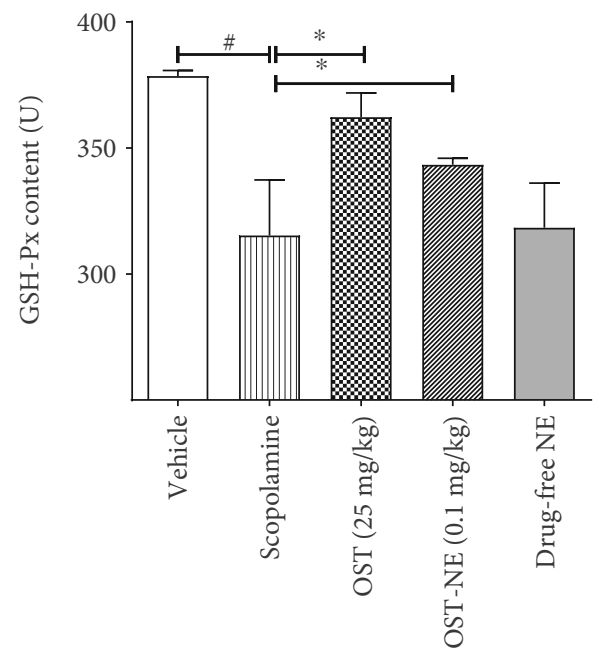

(e)

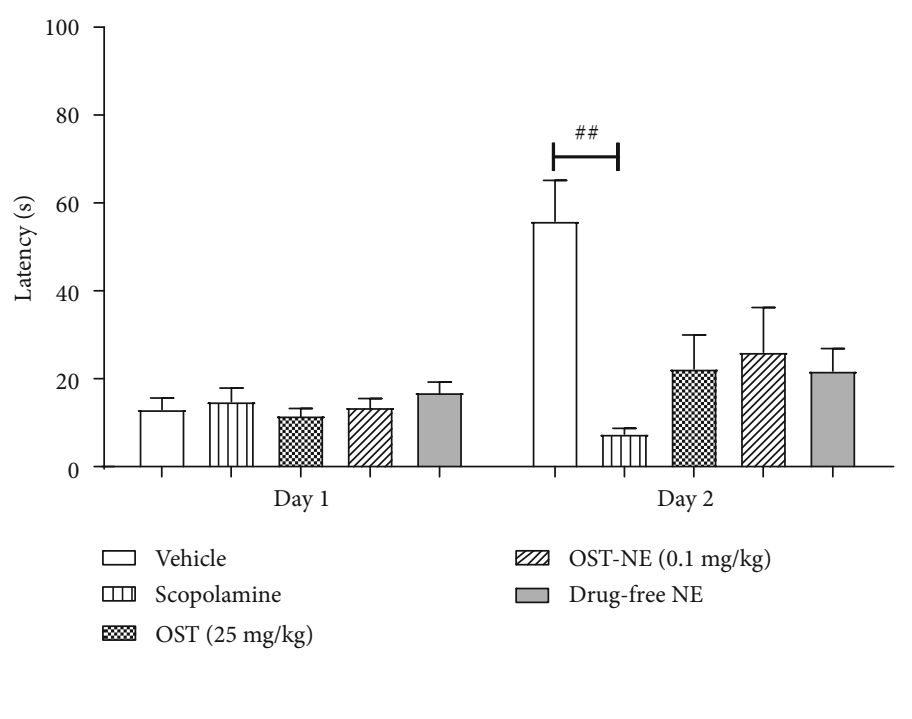

(b)

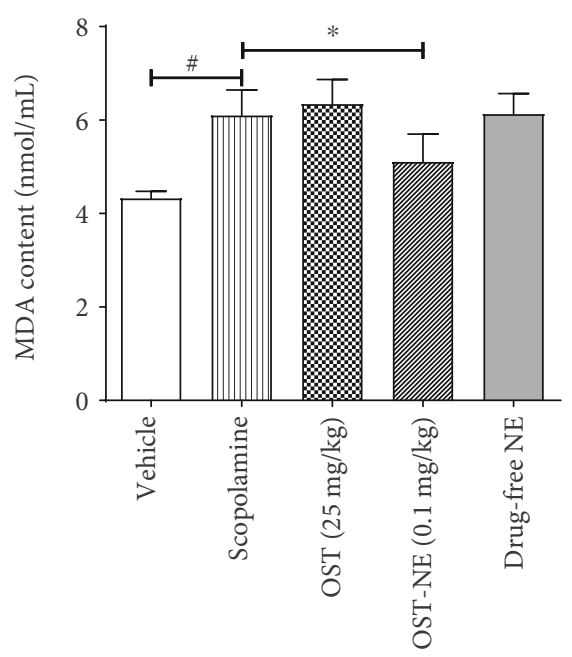

(d)

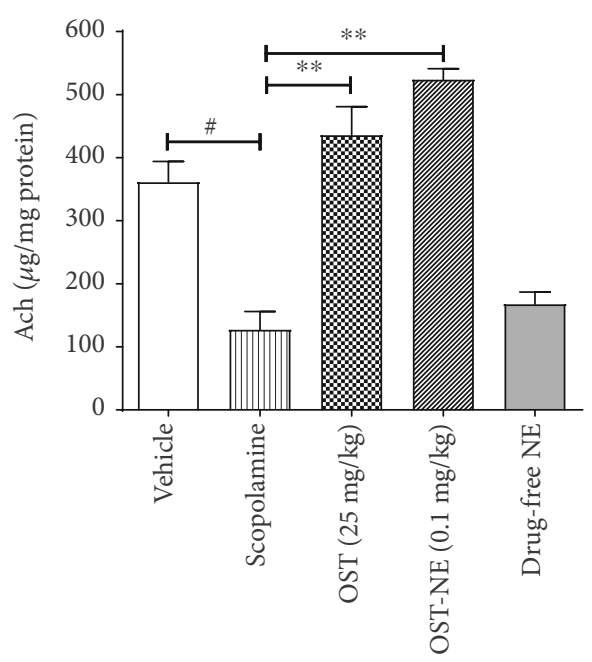

(f)

FIgURE 11: Continued. 


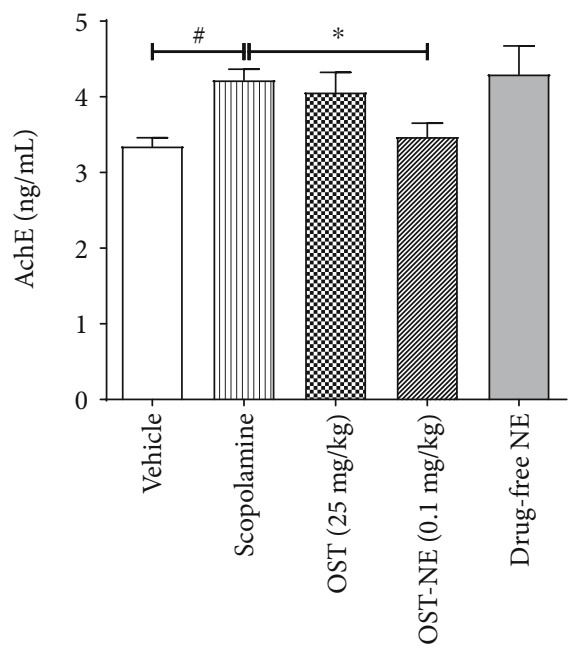

(g)

FIGURE 11: Effects of OST-NE on memory function, oxidative stress, and cholinergic pathway in scopolamine-induced mice. (a) The number crossing the platform during the space exploration in the Morris water maze test. (b) Latency to step to the dark chamber in the light and dark box test. (c-e) Levels of oxidative stress markers (SOD, MDA, and GSH-Px) in the serum. (f) Ach level in the cerebral cortex. (g) AchE level in the hippocampus. (a, b) $n=10-12$ per group, (c-g) $n=5-6$ per group. ${ }^{\#} P<0.05$ and ${ }^{\# \#} P<0.01$ vs. vehicle group, ${ }^{*} P<0.05$ and ${ }^{* *} P<0.01$ vs. scopolamine group. Drug-free NE, blank nanoemulsion.

which may be through regulating the apoptosis pathway, oxidative stress, and the cholinergic system. These findings suggest that OST-NE can be used as a possible alternative to improve its bioavailability and that OST-NE may have a potential curative effect in the prevention and treatment of AD.

\section{Data Availability}

The data are available from the corresponding author upon request.

\section{Conflicts of Interest}

No competing interests are present.

\section{Acknowledgments}

This work was supported by grants from the Key Research and Development Project of Shandong Province (2019GSF108069), the National Natural Science Foundation of China (81703901), the Development Project of Traditional Chinese Medicine Science and Technology in Shandong Province (2019-0361), the Shandong Province Natural Science Foundation of China (ZR2016HB56), and the Academic Promotion Program of Shandong First Medical University (2019LJ003).

\section{References}

[1] E. Joe and J. M. Ringman, "Cognitive symptoms of Alzheimer's disease: clinical management and prevention," BMJ, vol. $367,2019$.

[2] M. Agrawal, S. Saraf, S. Saraf et al., "Nose-to-brain drug delivery: an update on clinical challenges and progress towards approval of anti-Alzheimer drugs," Journal of Controlled Release, vol. 281, pp. 139-177, 2018.

[3] "2020 Alzheimer's disease facts and figures," Alzheimers \& Dementia, vol. 16, no. 3, pp. 391-460, 2020.

[4] P.-C. Liao, S.-C. Chien, C.-L. Ho et al., "Osthole regulates inflammatory mediator expression through modulating NFkappa B, mitogen-activated protein kinases, protein kinase $\mathrm{C}$, and reactive oxygen species," Journal of Agricultural and Food Chemistry, vol. 58, no. 19, pp. 10445-10451, 2010.

[5] X. P. Fu and C. H. Hong, "Osthole attenuates mouse atopic dermatitis by inhibiting thymic stromal lymphopoietin production from keratinocytes," Experimental Dermatology, vol. 28, no. 5, pp. 561-567, 2019.

[6] Z. W. Chen, X. X. Mao, A. M. Liu et al., "Osthole, a natural coumarin improves cognitive impairments and BBB dysfunction after transient global brain ischemia in C57 BL/6J mice: involvement of Nrf2 pathway," Neurochemical Research, vol. 40, no. 1, pp. 186-194, 2015.

[7] Y. Hu, Q. Wen, W. Liang et al., "Osthole reverses beta-amyloid peptide cytotoxicity on neural cells by enhancing cyclic AMP response element-binding protein phosphorylation," Biological \& Pharmaceutical Bulletin, vol. 36, no. 12, pp. 1950-1958, 2013.

[8] X. Dai, C. Yin, Y. Zhang et al., "Osthole inhibits triple negative breast cancer cells by suppressing STAT3," Journal of Experimental \& Clinical Cancer Research, vol. 37, no. 1, 2018.

[9] Q. Chu, Y. Zhu, T. Cao et al., "Studies on the neuroprotection of osthole on glutamate-induced apoptotic cells and an Alzheimer's disease mouse model via modulation oxidative stress," Applied Biochemistry and Biotechnology, vol. 190, no. 2, pp. 634-644, 2020.

[10] Y. Yao, Z. Gao, W. Liang et al., "Osthole promotes neuronal differentiation and inhibits apoptosis via Wnt/beta-catenin signaling in an Alzheimer's disease model," Toxicology and Applied Pharmacology, vol. 289, no. 3, pp. 474-481, 2015. 
[11] Y. Jiao, L. Kong, Y. Yao et al., "Osthole decreases beta amyloid levels through up-regulation of miR-107 in Alzheimer's disease," Neuropharmacology, vol. 108, pp. 332-344, 2016.

[12] S.-H. Li, P. Gao, L.-T. Wang et al., "Osthole stimulated neural stem cells differentiation into neurons in an Alzheimer's disease cell model via upregulation of microRNA-9 and rescued the functional impairment of hippocampal neurons in APP/PS1 transgenic mice," Frontiers in Neuroscience, vol. 11, 2017.

[13] H. Xiao, Y. Wang, Y. Wu et al., "Osthole ameliorates cognitive impairments via augmenting neuronal population in APP / PS1 transgenic mice," Neuroscience Research, 2020.

[14] X. J. Hu, Y. Liu, X. F. Zhou et al., "Synthesis and characterization of low-toxicity $\mathrm{N}$-caprinoyl-N-trimethyl chitosan as selfassembled micelles carriers for osthole," International Journal of Nanomedicine, vol. 8, pp. 3543-3558, 2013.

[15] Y. Ma, Y. Zhang, Y. Zhai et al., "Development of a UPLCTQ/MS approach for the determination of eleven bioactive components in Haizao Yuhu Decoction plus-minus Haizao and Gancao drug combination after oral administration in a rat model of hypothyroidism," Molecules, vol. 22, no. 1, 2017.

[16] X. B. Hu, Y. Liu, Y. Y. Bei, J. Zhao, and X. N. Zhang, "Preparation of $\mathrm{pH}$-sensitive osthol-nanoparticles and its pharmacokinetics in rats," Chinese Journal of New Drugs, vol. 21, no. 5, pp. 490-497, 2012.

[17] A. A. Date and M. S. Nagarsenker, "Parenteral microemulsions: an overview," International Journal of Pharmaceutics, vol. 355, no. 1-2, pp. 19-30, 2008.

[18] T. Z. da Silva Marques, R. Santos-Oliveira, L. B. de Oliveira de Siqueira et al., "Development and characterization of a nanoemulsion containing propranolol for topical delivery," International Journal of Nanomedicine, vol. Volume 13, pp. 28272837, 2018.

[19] S. Md, S. Y. Gan, Y. H. Haw, C. L. Ho, S. Wong, and H. Choudhury, "_In vitro_neuroprotective effects of naringenin nanoemulsion against $\beta$-amyloid toxicity through the regulation of amyloidogenesis and tau phosphorylation," International Journal of Biological Macromolecules, vol. 118, pp. 1211-1219, 2018.

[20] B. Gaba, T. Khan, M. F. Haider et al., "Vitamin E loaded naringenin nanoemulsion via intranasal delivery for the management of oxidative stress in a 6-OHDA Parkinson's disease model," BioMed Research International, vol. 2019, 20 pages, 2019.

[21] H. Xie, L. Li, Y. Sun et al., "An available strategy for nasal brain transport of nanocomposite based on PAMAM dendrimers via in situ gel," Nanomaterials (Basel), vol. 9, no. 2, 2019.

[22] S. K. Bhattamisra, A. T. Shak, L. W. Xi et al., "Nose to brain delivery of rotigotine loaded chitosan nanoparticles in human SH-SY5Y neuroblastoma cells and animal model of Parkinson's disease," International Journal of Pharmaceutics, vol. 579, 2020.

[23] A. Kaur, K. Nigam, S. Srivastava, A. Tyagi, and S. Dang, "Memantine nanoemulsion: a new approach to treat Alzheimer's disease," Journal of Microencapsulation, vol. 37, no. 5, pp. 355-365, 2020.

[24] A. Kaur, K. Nigam, I. Bhatnagar et al., "Treatment of Alzheimer's diseases using donepezil nanoemulsion: an intranasal approach," Drug Delivery and Translational Research, vol. 10, no. 6, pp. 1862-1875, 2020.

[25] X. R. Lou, R. Ren, Z. Y. Qian, and J. Yang, "HPLC determination of equilibrium solubility and apparent oil/water partition coefficient of limonin," Chinese Journal of Pharmaceutical Analysis, vol. 33, no. 4, pp. 1711-1714, 2011.

[26] S. Sawatdee, A. Atipairin, A. S. Yoon, T. Srichana, N. Changsan, and T. Suwandecha, "Formulation development of albendazole-loaded self-microemulsifying chewable tablets to enhance dissolution and bioavailability," Pharmaceutics, vol. 11, no. 3, 2019.

[27] Q. Zhang, X. Jiang, W. Jiang, W. Lu, L. Su, and Z. Shi, "Preparation of nimodipine-loaded microemulsion for intranasal delivery and evaluation on the targeting efficiency to the brain," International Journal of Pharmaceutics, vol. 275, no. 1-2, pp. 85-96, 2004.

[28] S. A. Shah, F. U. Amin, M. Khan et al., "Anthocyanins abrogate glutamate-induced AMPK activation, oxidative stress, neuroinflammation, and neurodegeneration in postnatal rat brain," Journal of Neuroinflammation, vol. 13, 2016.

[29] X. Q. Hou, H. P. Song, Y. B. Chen et al., "Effects of BushenYizhi formula on age-related inflammation and oxidative stress in senescence-accelerated mice," Molecular Medicine Reports, vol. 17, no. 5, pp. 6947-6960, 2018.

[30] H. Xicoy, B. Wieringa, and G. J. M. Martens, "The SH-SY5Y cell line in Parkinson's disease research: a systematic reviewMolecular Neurodegeneration," vol. 12, 2017.

[31] D. Mastroeni, J. Nolz, O. M. Khdour et al., "Oligomeric amyloid $\beta$ preferentially targets neuronal and not glial mitochondrial-encoded mRNAs," Alzheimers \& Dementia, vol. 14, no. 6, pp. 775-786, 2018.

[32] V. Chinchalongporn, M. Shukla, and P. Govitrapong, "Melatonin ameliorates A beta(42)-induced alteration of beta APPprocessing secretases via the melatonin receptor through the Pin1/GSK3 beta/NF-kappa B pathway in SH-SY5Y cells," Journal of Pineal Research, vol. 64, no. 4, 2018.

[33] F. M. Ribeiro, L. B. Vieira, R. G. W. Pires, R. P. Olmo, and S. S. G. Ferguson, "Metabotropic glutamate receptors and neurodegenerative diseases," Pharmacological Research, vol. 115, pp. 179-191, 2017.

[34] W. Danysz and C. G. Parsons, “Alzheimer's disease, $\beta$-amyloid, glutamate, NMDA receptors and memantine - searching for the connections," British Journal of Pharmacology, vol. 167, no. 2, pp. 324-352, 2012.

[35] D. T. Loo, "In situ detection of apoptosis by the TUNEL assay: an overview of techniques," DNA Damage Detection In Situ, Ex Vivo, and In Vivo, Methods in Molecular Biology, vol. 682, pp. 3-13, 2011.

[36] R. Mirzayans and D. Murray, "Do TUNEL and other apoptosis assays detect cell death in preclinical studies?," International Journal of Molecular Sciences, vol. 21, no. 23, 2020.

[37] A. Tortosa, E. López, and I. Ferrer, "Bcl-2 and Bax protein expression in Alzheimer's disease," Acta Neuropathologica, vol. 95, no. 4, pp. 407-412, 1998.

[38] N. Louneva, J. W. Cohen, L. Y. Han et al., "Caspase-3 is enriched in postsynaptic densities and increased in Alzheimer's disease," American Journal of Pathology, vol. 173, no. 5, pp. 1488-1495, 2008.

[39] M. Obulesu and M. J. Lakshmi, “Apoptosis in Alzheimer's disease: an understanding of the physiology, pathology and therapeutic avenues," Neurochemical Research, vol. 39, no. 12, pp. 2301-2312, 2014.

[40] K. Cosentino and A. J. García-Sáez, "Bax and Bak pores: are we closing the circle?," Trends in Cell Biology, vol. 27, no. 4, pp. $266-275,2017$. 
[41] S. Nagata, "Apoptosis and clearance of apoptotic cells," Annual Review of Immunology, vol. 36, no. 1, pp. 489-517, 2018.

[42] J. P. Teixeira, A. A. de Castro, F. V. Soares, E. F. F. da Cunha, and T. C. Ramalho, "Future therapeutic perspectives into the Alzheimer's disease targeting the oxidative stress hypothesis," Molecules, vol. 24, no. 23, 2019.

[43] P. Poprac, K. Jomova, M. Simunkova, V. Kollar, C. J. Rhodes, and M. Valko, "Targeting free radicals in oxidative stressrelated human diseases," Trends in Pharmacological Sciences, vol. 38, no. 7, pp. 592-607, 2017.

[44] R. Sultana, M. Perluigi, and D. A. Butterfield, "Lipid peroxidation triggers neurodegeneration: a redox proteomics view into the Alzheimer disease brain," Free Radical Biology and Medicine, vol. 62, pp. 157-169, 2013.

[45] P. T. Francis, A. M. Palmer, M. Snape, and G. K. Wilcock, "The cholinergic hypothesis of Alzheimer's disease: a review of progress," Journal of Neurology, Neurosurgery \& Psychiatry, vol. 66, no. 2, pp. 137-147, 1999.

[46] Q. Zou, Y. Fang, Y. Zhao et al., "Synthesis and in vitro photocytotoxicity of coumarin derivatives for one- and two-photon excited photodynamic therapy," J Med Chem, vol. 56, no. 13, pp. 5288-5894, 2013.

[47] N. Garti, V. Clement, M. Leser, A. Aserin, and M. Fanun, "Sucrose ester microemulsions," Journal of Molecular Liquids, vol. 80, no. 2-3, pp. 253-296, 1999.

[48] Y. H. Cho, S. Kim, E. K. Bae, C. K. Mok, and J. Park, "Formulation of a cosurfactant-free $\mathrm{O} / \mathrm{W}$ microemulsion using nonionic surfactant mixtures," Journal of Food Science, vol. 73, no. 3, pp. E115-E121, 2008.

[49] P. Li, A. Ghosh, R. F. Wagner, S. Krill, Y. M. Joshi, and A. T. M. Serajuddin, "Effect of combined use of nonionic surfactant on formation of oil-in-water microemulsions," Int J Pharm, vol. 288, no. 1, pp. 27-34, 2005.

[50] H. Tang, S. Xiang, X. Li, J. Zhou, and C. Kuang, "Preparation and in vitro performance evaluation of resveratrol for oral self-microemulsion," Plos One, vol. 14, no. 4, 2019.

[51] S. R. Pailla, S. Talluri, N. Rangaraj et al., "Intranasal zotepine nanosuspension: intended for improved brain distribution in rats," Daru, vol. 27, no. 2, pp. 541-556, 2019.

[52] A. Mistry, S. Z. Glud, J. Kjems et al., "Effect of physicochemical properties on intranasal nanoparticle transit into murine olfactory epithelium," Journal of Drug Targeting, vol. 17, no. 7, pp. 543-552, 2009.

[53] M. R. Hynd, H. L. Scott, and P. R. Dodd, "Glutamate-mediated excitotoxicity and neurodegeneration in Alzheimer's disease," Neurochemistry International, vol. 45, no. 5, pp. 583-595, 2004.

[54] E. Mazzio, J. Huber, S. Darling, N. Harris, and K. F. A. Soliman, "Effect of antioxidants on l-glutamate and _ $\mathrm{N}_{-}$ -methyl-4-phenylpyridinium ion induced-neurotoxicity in PC12 cells," Neurotoxicology, vol. 22, no. 2, pp. 283-288, 2001.

[55] P. Giannakopoulos, E. Kövari, A. Savioz et al., "Differential distribution of presenilin-1, Bax, and Bcl-X-L in Alzheimer's disease and frontotemporal dementia," Acta Neuropathologica, vol. 98, no. 2, pp. 141-149, 1999.

[56] J. Karch and J. D. Molkentin, "Regulated necrotic cell death the passive aggressive side of Bax and Bak," Circulation Research, vol. 116, no. 11, pp. 1800-1809, 2015.

[57] S.-J. Yang, A. R. Han, E.-A. Kim et al., "KHG21834 attenuates glutamate-induced mitochondrial damage, apoptosis, and
NLRP3 inflammasome activation in SH-SY5Y human neuroblastoma cells," European Journal of Pharmacology, vol. 856, 2019.

[58] H. Li, W. Han, H. Wang et al., "Tanshinone IIA inhibits glutamate-induced oxidative toxicity through prevention of mitochondrial dysfunction and suppression of MAPK activation in SH-SY5Y human neuroblastoma cells," Oxidative Medicine and Cellular Longevity, vol., vol. 2017, 2017.

[59] S. Krishnan and P. Rani, "Evaluation of selenium, redox status and their association with plasma amyloid/tau in Alzheimer's disease," Biological Trace Element Research, vol. 158, no. 2, pp. 158-165, 2014.

[60] M. P. Fink, "Reactive oxygen species as mediators of organ dysfunction caused by sepsis, acute respiratory distress syndrome, or hemorrhagic shock: : potential benefits of resuscitation with Ringer's ethyl pyruvate solution," Current Opinion in Clinical Nutrition and Metabolic Care, vol. 5, no. 2, pp. 167174, 2002.

[61] L. Cong, C. Cao, Y. Cheng, and X.-Y. Qin, "Green tea polyphenols attenuated glutamate excitotoxicity via antioxidative and antiapoptotic pathway in the primary cultured cortical neurons," Oxidative Medicine and Cellular Longevity, vol. 2016, 2016.

[62] J. Zhang, J. Wang, G.-S. Zhou et al., "Studies of the antiamnesic effects and mechanisms of single and combined use of donepezil and ginkgo ketoester tablet on scopolamineinduced memory impairment in mice," Oxidative Medicine and Cellular Longevity, vol. 2019, 2019.

[63] S. Dianzhi and T. C. Laboratory, "Clinical significance of oxidative stress related indexes and A-beta levels in the serum of patients Alzheimer's disease," China Medical Herald, vol. 14, no. 7, pp. 117-120, 2017.

[64] S.-P. Li, Y.-W. Wang, S.-L. Qi et al., “Analogous $\beta$-Carboline Alkaloids Harmaline and Harmine Ameliorate ScopolamineInduced Cognition Dysfunction by Attenuating Acetylcholinesterase Activity, Oxidative Stress, and Inflammation in Mice," Frontiers in Pharmacology, vol. 9, 2018.

[65] H. Hampel, M. M. Mesulam, A. C. Cuello et al., "The cholinergic system in the pathophysiology and treatment of Alzheimer's disease," Brain, vol. 141, no. 7, pp. 1917-1933, 2018. 